\title{
Design Core Competence Diagnosis: A Case From the Automotive Industry
}

\author{
Éric Bonjour and Jean-Pierre Micaëlli
}

\begin{abstract}
-1990's have been marked by significant changes both in the strategic management field, with the development of competence-based management and the use of the concept of valuecreating network, and in the design management field, with the diffusion of matrix-based tools that help to manage the interdependencies between three domains of design projects: product, process, and organization. Few researchers have helped to link these two fields. However, design managers need to use these fields closely together in order to enhance the firm's sustainable competitiveness. Indeed specialists of engineering management have already underlined that design organizations are responsible for the development of lines of products that have to satisfy distinctive stakeholders' requirements. Thus, design organizations strongly contribute to the firm's core competence. In this paper, we outline a method for diagnosing design core competence. We intend to couple strategic management concepts and design management concepts to represent and evaluate design core competence in relation to the product, process, and organizational architectures. The proposed method aims to highlight crucial design organizations, which should require particular managerial attention. The method has been researched and constructed in collaboration with a car design office, and applied in the case of a new robotized gearbox design.
\end{abstract}

Index Terms-Corporate core competence, design structure matrix (DSM), organization design, project and R\&D management, project teams.

\section{INTRODUCTION}

$\mathbf{F}$ OR a long time, managers and researchers in strategic management have admitted that brands, patents, and more generally, product innovations are key variables to distinguish a firm from its competitors. But the last two decades have been marked by significant conceptual changes in their way of thinking [1]. They wish "to open the "black box" of the firm to investigate what distinguishes firms internally from each other" [2]. Leading firms own rare, specific, inimitable assets [3], "tacit" knowledge or capabilities [4], or core competences, which enable

Manuscript received April 21, 2008; revised August 8, 2008, January 1, 2009, May 14, 2009, July 17, 2009, and September 2, 2009. Review of this manuscript was arranged by Department Editor J. K Pinto.

É. Bonjour is with the Department of Automatic Control and MicroMechatronic Systems, Franche-Comté Electronique Mécanique Thermique et Optique - Sciences et Technologies (FEMTO-ST) Institute, University of Franche-Comté (UFC)/Ecole Natioanle Supérieure de Mécanique et des Microtechniques (ENSMM)/University of Technology of BelfortMontbéliard (UTBM), Unités Mixtes de Recherche (UMR) Centre National de la Recherche Scientifique (CNRS) 6174, Besançon 25000, France (e-mail: eric.bonjour@ens2m.fr).

J.-P. Micaëlli is with the STOICA Research Team, Institut National des Sciences Appliquées Lyon, University of Lyon, Villeurbanne Cedex 69621, France (e-mail: jean-pierre.micaelli@insa-lyon.fr).

Color versions of one or more of the figures in this paper are available online at http://ieeexplore.ieee.org.

Digital Object Identifier 10.1109/TEM.2009.2036838 them to build and sustain their competitive advantage when their competitors cannot do so [5]. One recommends that these firms focus on these assets, capabilities or competences in order to "bundle" them, to "deploy" them, to "leverage" them [6], and outsource all their noncore activities [7]. Such a "make or buy" recommendation is sensible because the identification of corporate core competence is rather difficult. Corporate core competence has both holistic and evolutionary properties. As a holistic concept, it refers both to capabilities of a set of organizations (offices, departments, skill networks, teams, etc.) and to the nature of the "routines" [8]. Routines correspond to the ways in which the actors who are integrated in the so-called organizations collectively do something (cooperation, coordination, bargaining, collective learning, etc.) [8], [9]. Moreover, corporate core competence is not a well-defined fixed asset, contrary to what the resource-based view might suggest [3], [6]. The scope and the content of a given core competence are continuously modified by not only market, organizational or technological threats, or opportunities [5], but also by organizational learning.

The issue concerning the identification, evaluation, and building of corporate core competence [9], [10] continues to open promising ways for researchers and practitioners [6]. In this paper, we shall not address this issue from a general viewpoint, but from a specific one focused on design. Our purpose will be to show how to make the concept of core competence operational in the specific field of design. This focus on design can be explained easily.

Firstly, this activity strongly contributes to the product's competitiveness and to the firm's sustainable competitiveness (that is to say, the whole corporate core competence). Design core competence refers to the fact that the capabilities of design organizations (teams, departments, offices within the manufacturers, and their suppliers) significantly contribute to the development of corporate core competence. Design organizations can be considered as networks of actors (teams, designers, and managers), whose skills and routines concern the way, they develop new products, composed of interdependent components (structured by a product architecture), coordinate their interdependent tasks (structured by a process architecture), and exchange information (structured by an organizational architecture). Note that the terms "structure" and "architecture" are considered as being interchangeable throughout this paper. However, to be consistent, we use more particularly the terms: product architecture, process architecture, and organizational architecture. These terms have already been used by specialists of engineering management [11], [12]. Briefly, architecture corresponds to a designable and manageable set of elements (components, tasks, and actors) and the ways in which these elements interact. 
Secondly, the scope of the design core competence that each design manager takes into account is a complex system that should be identified, analyzed, evaluated, and rebuilt [13]-[16]. These last activities require close collaboration among the different design managers (program manager, product development manager, system architect, project manager (MGT), etc.). The quite recent "competence movement" [10] does not offer mature managerial tools to support these activities, because of the intrinsic complexity of its object.

In this paper, we do not intend to meet all the competencefocused needs of the design managers, but rather to propose an approach for identifying the structure and diagnosing design core competence in relation to models concerning organizational, process, and product architectures. As suggest some strategic management theorists [6], we shall apply this approach in a particular context, i.e., the complex automotive design organized according to the principles of systems engineering and involving the design offices of both the automaker and its suppliers. All these organizations are part of a "value-creating network" [17], that is to say, a design organization involving several independent firms, which contribute to a global value chain by coordinating their own value chains and design processes, making their activities more cooperative, offering a mutual "operational assistance" [18], and sharing their development costs, resources, practices, data, knowledge, and innovation projects. Thus, an organizational equilibrium is obtained between the contributions and retributions of the automaker and its suppliers. In the specific case of the automotive industry, the outcome of such a value-creating network is either the whole car or one of its main subsystems: body, passenger compartment, cockpit, electric network, powertrain system, etc. An automotive valuecreating network integrates within common projects and teams the automaker as an "orchestrator" [19] and a set of "module suppliers" (first tier supplier), and possibly tier 2 down to tier $n$ suppliers also [20]. Finally, design core competence is not a bundle or a bulk of designers' skills, and design organizations' capabilities and routines. We aim to show that it is convenient to use well-known engineering tools like dependency matrices [design structure matrix (DSM) and domain mapping matrix (DMM)] to represent the architecture of a design core competence, and to highlight crucial design organizations and key roles.

The remainder of this paper is structured as follows. Section II develops a brief literature review of the concepts, we propose and are used in the method. Section III presents the method, which helps to represent the structure and to evaluate design core competence. Section IV describes its application in the case of the development of a robotized gearbox, and finally, Section V discusses the results obtained.

\section{LITERATURE REVIEW}

This section sums up the research related to the design core competence management. It also presents the global concept of corporate core competence, the principles of systems engineering, and the matrix-based models related to product, process, and organizational architectures. Finally, it points out existing and missing links between research related to core competence management and other research fields concerning product architecture and design organization.

\section{A. From Corporate to Design Core Competence}

In management literature, the concept of corporate core competence has been used, since the 1990's to understand internal and particular factors, which explain the firm's differentiation and specialization [1], [6], [7], [21]. Strategic management researchers have tried to distinguish between the concept of core competence and those of asset, skill, routine, and capability [4], [5]. A consensus appears between them. Thus, functionally, corporate core competence is a "dynamic capability" [8], which produces an expected sustainable competitive advantage and plays a key role as a "gateway to tomorrow's markets" [21]. It does not refer to the firm's routines or capabilities, which are related to a particular current product. It concerns the distinctive future line of products, which the firm intends to design, manufacture, and sell. This line of products can strengthen the firm's position on the market or enable its diversification by creating a leading position in a new market. Corporate core competence is then a future and product lineoriented concept. Researchers have proposed a set of strategic criteria, which is useful to establish if an identified capability can be considered as a corporate core competence or not. This aspect has been greatly documented in literature, probably because it allows well-known multicriteria decision methods to be used, e.g., scoring or diagnosis tools [22], [23]. The criteria used to discriminate a corporate core competence depend on the evaluator's viewpoint. For an external evaluator (customer, competitor, supplier, researcher, etc.), core competence value refers to its rareness, its inimitability, and its nonsubstitutability [1], [3], [5], [6], [10], [21], [22]. From this point of view, the concept of core competence is very close to that of resource. For an internal evaluator (design manager, designer, etc.), core competence value also depends on three main inducers.

1) Its tacit and contingent nature.

2) Its generality. A core competence can be replicated. It can be reused from one product [5], design organization, or project to another.

3) Its compliance with the other bargaining, managerial or technological routines, and the capabilities the firm has already developed.

At the most elementary level, design core competences are embedded in the designers and design managers who are involved in design organizations. These actors and organizations contribute to the firm's sustainable competitive advantage because of following.

1) Insight into their customers' future values, needs or expectations [7], [21].

2) Knowledge about weaknesses and strengths of rival firms, and the technologies the firm (or its industry) [6] has adopted and assimilated.

3) Knowledge about technological opportunities.

4) Dynamic capabilities to create in time, new lines of products; 
5) Operational capabilities to improve the design processes' efficiency (delay, cost, quality, risk management, etc.).

Dynamic capabilities can produce incremental or "sustaining" [24] innovations that improve existing solutions by adding new functionalities, modifying architecture, human-machine interface, or form design, etc. They can also induce a main change in the firm's technological trajectory if they suppose the removal of the technological and organizational barriers [7]. It is the case when the firm hybridizes scattered technologies (radio and telephone in the case of mobile phones) [7] or explores new product lines (polyvalent electrical cars instead of classical cars with a thermal engine) [5].

Moreover, researchers link the sustainable competitive advantage induced by the corporate core competence to a value chain [7]. Therefore, the corporate core competence is considered as the set of activities, which must be internalized. However, this approach is too global [6]. It does not specify, which aspects of the design activity effectively contribute to the firm's sustainable competitive advantage: Are they linked to the fulfillment of distinctive requirements concerning the line of products? To the capabilities of the design organizations? To the process and organizational architectures, which combine the design capabilities? It is worth noting that despite its importance, little research has examined how the organizational architectures embody the design core competence.

\section{B. Systems Engineering}

Since the 1990's, the number of the systems engineering standards has grown to enable clients and contractors to master the development of systems, which are more and more complex. We can mention, without being exhaustive: MIL STD 499, EIA-ANSI 632, IEEE 1220, and ISO 15288. To put it briefly, the purpose of systems engineering is to organize complex design, so that the designed system achieves all the environmental and stakeholders' requirements, which are related to its entire life cycle. Systems engineering is clearly focused on both products and design processes. System complexity when taken into account by promoters of systems engineering induces at least three consequences.

1) Its development requires the decomposition into different interrelated modules (modularization) and layers (stratification).

2) At each layer, the design process is organized according to a clear division and coordination of different types of processes: bargaining (agreement or purchase versus offer), managerial (project or team management, etc.), support (prototyping, tests, etc.), and technical (system definition, functional analysis, architecture, system integration, etc.). Design teams are involved in the technical process, which is a sequence of activities that may be represented by the "V-cycle model" [25], a top-down approach (specification and design) followed by a bottom-up one (integration and validation).

3) The holistic stages, which concern system definition, architecture, and integration, are crucial.

Architecture and integration are required when designers have to cope with a high level of complexity [26]. Thus, architecture is not only a set of interrelated elements (internal view), but also an entity that integrates elements to satisfy all the requirements (external view). In the case of the architecture of a complex system, there is no trivial relation between the list of requirements and the set of components, and it is necessary to cluster them, in order to assign comprehensible and manageable work packages (or building blocks) to design teams. Systems engineering principles help the system architect to create subsystems according to a design process that can be decomposed into design tasks. These tasks are carried out by design organizations, and are then, supported by their capabilities [4], [8]. The integration of all the capabilities of the organizations is carried out to produce the whole design core competency.

\section{Architecture Design}

As mentioned earlier, the systems engineering framework is mainly related to product, design process, and organization. Thus, in the early phase of system definition, design managers and system architects have to jointly define the preliminary architecture of the product, and the architectures of the design process and organization [14].

1) Product Architecture: Ulrich defines product architecture as "the scheme by which the function of a product is allocated to physical components" [27]. According to this author, product architecture consists of following.

1) The arrangement of functional elements, or the function structure.

2) The mapping from functional elements to physical components.

3) The specification of the interfaces between components.

A key issue concerning product architecture is how to define the concept of module. Fortunately, there is a common way of defining it by only focusing on interactions between elements [28]. In addition, Browning defines "integrative elements" as interacting with all of the modules without belonging to a module [29].

Another key point concerning product architecture is the degree to which it is modular or integral. In modular architectures, the functions of the product map its physical components oneto-one, following Suh's "uncoupled design" principles [30]. At the other extreme, in "integral architectures", several product functions are linked to a single component or a small number of components. Consequently, system architects define modular product architectures with the following purposes.

1) Economies of scale (reusability of solutions from a product or project to another one) and economies of scope (production of a wide product family [31] or line by combining low-cost modules, which are specialized and even mass-produced [9]).

2) Organizational learning. Greater clarity in targeting useful organizational learning at both intra and intermodular levels [32] (specialized and integrative learning) is enabled by modular architectures.

3) A controlled introduction of new and risky solutions [33].

4) A minimization of the "transaction costs" [34]. Modularization reduces the bargaining expenses. It helps to precisely define the requirements of the module, which 
each team has to satisfy. It also reduces coordination efforts among design organizations involved in a common project.

From an "analytical perspective" [7], a modular architecture may be an ideal pattern. But in real design situations, designers have to make a tradeoff between modular and integral architectures [35].

2) Architectures of the Design Process and Organization: Architecture refers not only to product, but also to organization design. Thus, the functional view of the organization corresponds to the development process that has to meet the goals of the project. This process is decomposed into tasks. The concrete view corresponds to all the teams, which make up the global design organization (internal or suppliers' design teams), and which may be decomposed into smaller design organizations and individual designers. Key managerial decisions concern the allocation of design teams to the design tasks. The teams are in charge of carrying out the assigned tasks.

In complex product development projects using the principles of systems engineering, several teams develop the components, the modules or subsystems, and work to integrate all of these components to create the final product. Sosa, Eppinger, and Rowles, call "modular teams" those, which design modular systems, and "integrative teams" those, which design integrative systems [36], [37]. Browning suggests that "integrated product teams" bring cross-functional members together to achieve the development of particular subsystems or system components [38]. He adds that different levels of system teams may be required in the case of large projects. System teams may be split up into subsystems teams, components teams, and functional support groups. It is worth noting that the capabilities of modular teams are usually more specialized than those of integrative teams. However, if a team has to design a mechatronic module (or subsystem), then the adjective specialized does not refer to a single well-known discipline (mechanics, hydraulic, etc.), but rather to a coherent core of several disciplines required by the design of the multiphysical module.

3) Matrix-based Architecture Models: Matrix-based architecture models provide useful representations of internal and external interactions (or dependencies), which link three project domains: product, design process, and design organization [39]. They are increasingly being used, as they are able to support different research goals, for example, product modularization [40], [41], analysis of technical interactions either within the products [42] or within the project organization [35], and change propagation analysis [43]. In fact, there are two subtypes of dependency matrices [44].

1) Interdomains matrices, which represent dependencies between two domains. These matrices are called incidence matrices [45], traceability, and allocation matrices (IEEE Std 1220, 2005) or DMM [46]. They have to ensure the cohesion between the product subdomains [47] and more generally, between project domains [11].

2) Intradomain matrices, which represent dependencies between elements within the same domain, e.g., between components. These matrices are usually called DSM [29], [37], [48].
DSM are now popular modeling and analysis tools, especially for purposes of decomposition and integration as they display the relationships between elements of a system in a compact and visual format [42]. Thus, they are used to identify projectdomain architectures (for a literature review, see [29]): the product architecture, the architecture of the design process [49]-[51], and the organizational architecture, which corresponds to the decomposition of the projects into different teams or communities [35], [45].

A few researchers recently proposed to combine several DSM and the connecting DMM [11], [46], [47], [52] in order to link multiple domains, thus creating a multiple domain matrix (MDM). Danilovic and Leisner use DMM to link important module areas (which compose end product architecture) and existing design skill areas [13]. Their aim is to identify and align crucial skill areas related to major module areas (a set of modules relatively homogeneous from a competence perspective).

\section{Synthesis}

A recent review concerning competence management underlines the need for models and tools, which help managers to make competence-based management more effective by linking operational and strategic decisions [53]. As mentioned in the previous part, in the field of strategic management, some concepts help to identify or evaluate core competencies. In the field of design management, matrix-based architecture models can represent the architectures of the product, process, and organization. Little work has helped to link these two fields. However, design managers and systems architects who are responsible for the development of complex products need to combine them very closely. Modularization is considered as a valuable way for defining modules as common objects of value-creating networks [20] and for facilitating the development of capabilities based on modular organizational routines [9]. A few researchers have recommended that the product architecture should appropriately mirror (or align, match) the architecture of design organizations, and thus, the value-creating network that develops it [12], [14]-[16], [39], [54].

Design managers could use DMM and DSM to identify areas, where a value-creating network could be built in order to exploit identified internal, addressed, and outsourced design core competencies. Thus, the scope of dependency matrices should be extended, from an "analytical perspective" [7] and an operational content to a strategic one. DSM or DMM must not be considered only as formal models although they may be rearranged by clustering or sequencing algorithms separately. The combination of dependency matrices must be considered as a managerial tool, not as an optimization method only. Our purpose is not to answer the following question: How to modularize product and define efficient design organizations? But rather, how to use dependency matrices to represent the architecture of design core competence? In this paper, we propose their use to give a static architecture of design core competency. Such representations are helpful and provide a common language for design managers and system architects. The questions we have mentioned earlier are very general. In the remainder of this 


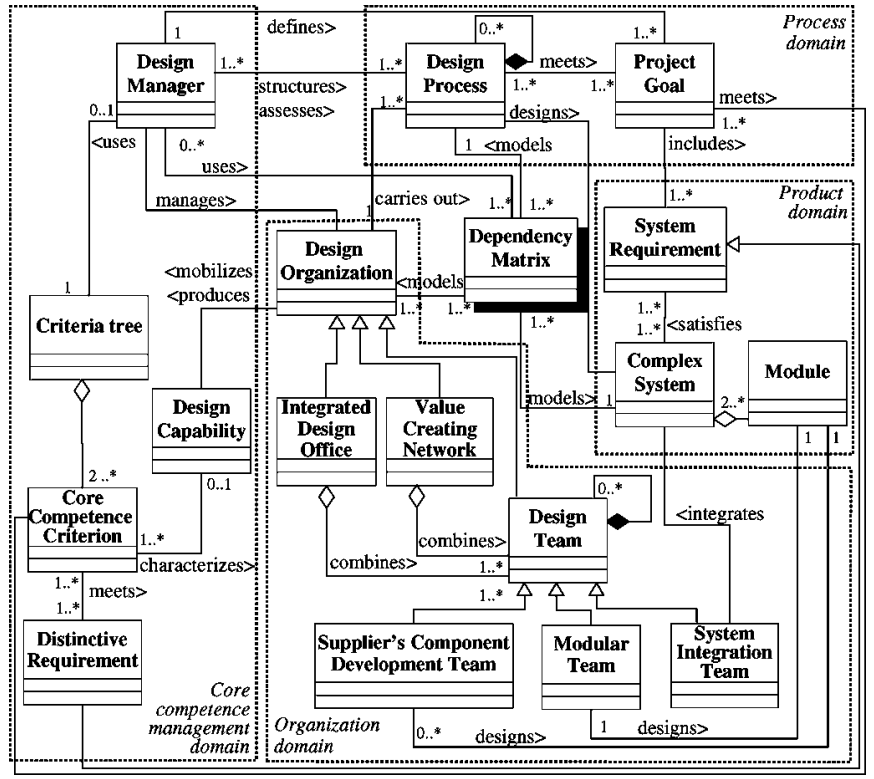

Fig. 1. Design core competence framework.

paper, we focus on the design of powertrains relying on complex architectures, developed by integrated product teams.

\section{Approach to DiAgnose Design CoRe COMPETENCE}

In this section, we briefly present an approach for identifying the architecture and evaluating global design core competence in the case of complex products. Firstly, we present key concepts of competence-based design management and secondly, we outline the proposed method for diagnosing design core competence.

\section{A. Conceptual Framework}

The conceptual framework we propose intends to represent the links between key concepts involved in the building of design core competence. These concepts refer to the capabilities of the design organizations and to the criteria used to appreciate if the capability of the global design organization is a core competence or not. This framework is presented by means of the unified modeling language (UML) class diagram in Fig. 1 [55]. Dependency matrices play the role of interconnecting models (in the center of the figure). Dependency matrices are seen as useful tools to model the architectures of product, design process, and organization along with their interdependencies. Thus, Fig. 1 integrates around the class called "dependency matrix" several domains related to product, design process, organization, and core competence management.

Product domain: The designed complex system has to satisfy system requirements and is decomposed into several modules.

Design process domain: The design process is organized and assessed by a design manager. It may be decomposed into tasks and has to meet the project goals.

Organization domain: Design organizations (integrated design office, value-creating network, and design teams) carry out design processes and tasks. They are organized, coached, evaluated, and represented by a design manager (system architect,
MGT, team manager, etc.). Design teams may be decomposed into smaller design teams. A system integration team is responsible for integrating the complex system whereas in-house modular teams and teams within the suppliers' design offices are in charge of developing modules and components.

Core competence domain: This domain integrates the concepts (distinctive requirement, design capability) and the tools (core competence criterion and criteria tree) used by design managers. Distinctive requirements and project goals have to meet the corresponding core competence criteria so as to judge if the final project outcome is successful or not. Design managers can use a criteria tree composed of core competence criteria to evaluate if the produced design capability is a core competence or not.

Firstly, this tree combines several criteria related to the value of the core competence estimated by an external or internal evaluator. Potential criteria are identified between brackets next. In the former case (external view), the focus is on market criteria (rareness and inimitability of the competence under evaluation) [3] or social criteria (its regulation advance and its social compliance). In the latter case (internal view), other criteria add new branches to the criteria tree. They are related to the effects of the evaluated capability on the leading firm's and suppliers' new routines. Does it help to increase the complexity of the outcome of the design activity (criterion: technical complexity)? Is it really sustainable and related to a perennial product line (criteria: generality and sustainability) [3]? Does it help the suppliers involved in the value-creating network to carry out the development of a whole "design module" efficiently [20]? Does it enhance long-term efficiency of the teams in charge of the module development and system integration (criteria: system integration capability or module development capability)? Is it easy to understand and to replicate for a competitor who wants to create a similar value-creating network (criterion: embeddedness)? Does it enhance cross-learning with first tier suppliers (criterion: cooperative value)?

Secondly, the value criteria related to design core competence are balanced with cost criteria. The main idea is easy to understand. The development of design capabilities, which support design core competence is an expensive process, which induces a global cost [3], [56]. The new capability can be supported by new purchased assets or newly hired experts or managers (criterion: acquisition cost). The context concerning the production of the new capability has to be remembered, understood, and explained (criterion: contextualization cost). One has to make the related knowledge explicit by using design models and knowledge management models (criterion: conceptualization cost). Last but not least, this conceptualized knowledge has to be capitalized in order to make its diffusion and its sustainability effective (criterion: capitalization cost). Fortunately, the more expensive this process is, the higher the barrier to entry related to the evaluated design capability is. Expressed differently, a core design competence has not only a great strategic value, it is also expensive to make it sustainable.

Coupling the project domains and the core competence domain: It is worth noting that in Fig. 1, there is no direct relationship between the dependency matrix and the criteria tree. 
Indeed, the design managers should use these two complementary tools. With the former tool, they represent the architectures of the project domains along with their couplings. With the latter tool, they evaluate the design capability produced by design organizations (which belong to the organization domain) with regard to distinctive requirements (which belong to the product domain) and project goals (which belong to the process domain). This requires a great change in strategic management practices as managers have to focus on organizational entities, design processes, project goals, and systems requirements simultaneously. There is no existing algorithm to couple the use of the so-called tools and domains automatically. Combining DSM and DMM is a quite recent approach, which does not propose mature and tested tools. However, partial couplings and propagations can be formalized, as it will be shown in this paper.

\section{B. Requirements and Steps of the Approach}

The approach we propose aims at supporting the activities of the design managers, which are related to core competence diagnosis. It is divided into five steps as follows.

1) Design contextualization. As is underlined by evolutionary economics and strategic management theorists, a core competence building is contingent and path-dependent [6], [8]. It refers to a specific context (type of requirements, product lines, economical constraints, design practices, etc.), the design managers have to take into account.

2) The identification of the expectations related to the design core competence. The aim of this step is to identify and elicit the core competence criteria the project team has to meet.

3) Modeling of product, process, and organizational architectures and their interdependencies. The aim is to propagate distinctive requirements through the product architecture and the design process architecture in order to qualitatively identify, which teams' capabilities contribute to meet them.

4) Identification of the value-creating network. The aim is to build a clear cartography of the relationships between the integrated design office and the set of teams within the suppliers involved in the design project.

5) Ex-postevaluation of the produced design capability. A qualitative evaluation of strategic criteria can be performed at the end of the system development project.

\section{Particular Case of the Robotized Gearbox Project}

This part presents a case study that concerns the organizational change process that transformed an old project organization, which designs mechanical gearboxes, into a new organization responsible for the development of more complex robotized gearboxes. We applied the proposed method to diagnose the resulting design capability. Our aim was to represent the architecture of the produced capability, to visualize how it had been embodied in the design teams involved in the valuecreating network, to evaluate it and to discuss its strengths and weaknesses.

\section{A. Design Contextualization}

The case described in the following sections comes from research collaboration (2000-2006) with a French automaker design office. This organization of 4400 designers is specialized in powertrain and chassis development. This design office took into consideration the principles of systems engineering, since 1997 when it was restructured, benefiting from a methodological transfer from aeronautics. It is responsible for both routine and innovative designs. It exploited well-known purely mechanical solutions, and then, ensured the technological continuity of the line of products. But it also had to produce a continuous flow of effective innovations, in order to offer differentiated cars, which would achieve strict requirements (drivability, safety, consumption, $\mathrm{CO}_{2}$ emissions, etc.). The following points explain why the powertrain system design is complex.

1) In functional terms, the size of the requirements list is important. The target level of each of them (safety, gas emission, consumption, drivability, etc.) is higher and higher. The contradictions between them are acute (e.g., a better safety at a lower weight, etc.).

2) In structural terms, each powertrain system includes tens of functional modules and thousands of components.

3) In behavioral terms, it is a dynamic system, which is used in many external environments. Moreover it is coupled to other dynamic subsystems (e.g., chassis).

Moreover, the powertain system is produced by massproduction manufacturing systems, which are organized following the principles of the "Toyota production system" [57]. The fixed costs are high. The powertain system has a longer lifecycle than the ones of vehicle models in which it is integrated. During its life, a powertrain knows several vintages and evolutions. Thus, designers have developed a product family, not a single product. Moreover, innovation is forecast and controlled. A technological continuity exists between the vintages of the product.

The presented case refers more particularly to a subsystem of the powertrain, which is the gearbox. Gearboxes are critical components of the vehicle cinematic chain. For a long time, gearboxes have been well-known mechanical systems. Innovation in this field has been more incremental than radical and there has been a clear dichotomy between manual and automatic gearboxes. The system studied is a new robotized gearbox, which is a technological hybrid between manual and automatic gearboxes. This technical solution is part of a growing class of modules in the automotive industry, which is that of mechatronic subsystems. The concept of the robotized gearbox is to plug a mechatronic actuator (ACT) on a standard manual gearbox with a low cost and a long life cycle. These last points explain how a robotized gearbox can act as an automatic gearbox, and be a cheap solution. There is a potential market for the robotized gearbox: customers who are interested in driving without being disturbed by gearshifting, but who cannot afford an automatic gearbox. Designers involved in the robotized gearbox project had to make what the biologist Stephen Jay Gould (19412002) has called "exaptation" [58]. That is to say, in the present case, exploit as far as possible the potential of current products 
(manual gearbox and compact electrical ACT), the capabilities of design organizations (automaker's design teams), and the growing capabilities of the suppliers involved in the development of subsystems (they try to offer the same solution to several automakers), to open a new product line. It is to be noted that the development of a robotized gearbox is neither a routine design, nor an advanced one.

\section{B. Identification of the Expectations Related to the Design Core Competence}

From the driver's point of view, a car can be considered as an object, which provides a set of services. These services concern the entire vehicle. Thus, design teams need to decompose them into well-defined expectations linked to the car subsystems, e.g., the powertain and the gearbox. The main distinctive requirements can be abstracted from the requirements or constraints allocated to the robotized gearbox.

1) Shifting gears at less than $250 \mathrm{~ms}$, for the feeling of security and the driver's pleasure (or drivability) given by this short time.

2) Contributing to the reduction of $\mathrm{CO}_{2}$ emissions (compliance with very strict Euro $\mathrm{V}$ standards), and to the improvement of fuel consumption.

3) Being as reliable as a manual gearbox.

4) Being an intermediate solution, between cheap manual gearboxes and expensive automatic ones.

In addition to this list of requirements, the goals of the robotized gearbox design project contribute to some of the core competence criteria. In this case, the expected gearbox design capabilities must do the following.

1 Give a provisory leadership in robotized gearboxes in the B segment of the car market (subcompact cars) and erase the place of the automatic gearbox in this segment.

2 Use the same manufacturing system as the one dedicated to a manual gearbox once again. This kind of production system is both capitalistic (high level of fixed costs), and well-known (it is nearly 20 years old). In other words, robotized gearboxes can be seen as an innovative variant of a gearbox platform.

3 Develop a line of products, which are compliant with environmental and social values.

4 Develop an in-house, technical, and organizational learning, which is related to the codevelopment of key mechatronic modules (specification, functional modeling, and validation).

5 Improve the efficiency of collaboration and cross-learning with first tier suppliers.

6 Improve operational performances of projects concerning future designs of mechatronic systems (in particular, the project risks must be managed rigorously, the project duration must be shorter than 120 weeks).

\section{Modeling of Product, Process, and Organizational Architectures and their Interdependencies.}

After identifying the context of the gearbox design and the design core competence expectations, we needed to model the

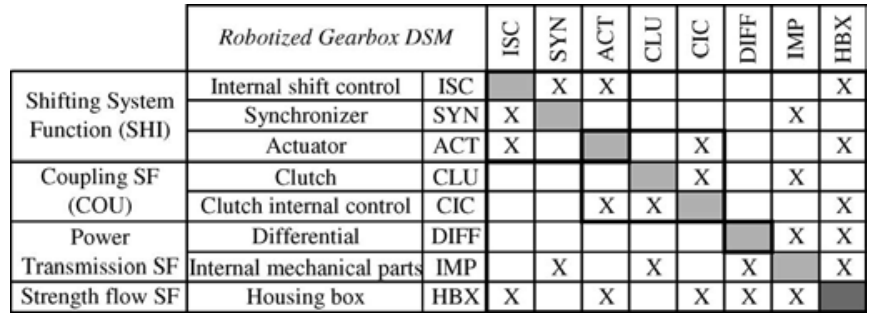

Fig. 2. Product DSM of the robotized gearbox.

dependencies between the product (here, a robotized gearbox), the design process, and the design organization. This needed to be done in order to estimate any possible impacts of distinctive requirements on design organizations, and to highlight crucial design organizations and their capabilities.

1) Product Architecture: Firstly, we interviewed design experts and architects who had a thorough understanding of gearbox architectures. The system architect identified four main system functions (SF): shifting, coupling, power transmission, and strength flow. For the transformation of a manual gearbox into a robotized one, an ACT was to replace the gearshift lever and the clutch pedal. The designed robotized gearbox was composed of eight components, and hundreds of parts. The mapping between functions and components was facilitated by the typicality of the architecture of the robotized gearbox. In this project, the system architect defined an architecture, where an electrical ACT acted both on the internal shift control (ISC) and the clutch internal control (CIC). Fig. 2 displays its hybrid architecture which was composed of following:

1) three modules (or modular subsystems): (ISC; synchronizer (SYN); ACT); (ACT; clutch (CLU); CIC); (differential (DIFF));

2) two integrative subsystems: they linked the other modules of the gearbox together, internal mechanical parts (IMP) from the inside and the housing box (HBX) from the outside.

In this product architecture, each module was directly linked to a system function. Concerning the integrative components, the "IMP" were linked to the differential through the fulfillment of the power transmission function. The HBX directly supported the strength function. Moreover, the system architect stressed that distinctive requirements were carried out by different functions. Drivability was carried out by a modular subsystem (system function: gearshifting; related components: ISC, SYN, and ACT). Power transmission and shifting functions contributed to fuel consumption improvement. Coupling and strength were internal functions. The technical risks management had identified the SYN and ACT as being the most critical components concerning reliability as the gear teeth of the SYN (form and material) had to be modified because of the high strength provided by the ACT. In addition, the ACT included electronic devices and its introduction was innovative. Consequently, the "gearshifting" subsystem had a significant impact on distinctive requirements.

2) Design Process Architecture: Once the robotized gearbox architecture was defined, we interviewed the project 


\begin{tabular}{|c|c|c|c|c|c|c|c|c|c|c|c|c|c|}
\hline & & $\bar{E}$ & 8 & 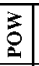 & 总 & $\begin{array}{lll} \\
\end{array}$ & & U & 8 & & & & $\overline{\underline{\prime}}$ \\
\hline Negociate specifications & 0RG1 & $\mathbf{x}$ & $\mathbf{x}$ & $\mathbf{x}$ & $\mathbf{x}$ & & & & & & & & \\
\hline Specify POW function & 1RG1 & & & $\mathbf{x}$ & & & & & & & & & \\
\hline Specify COU function & 1RG2 & & $\mathbf{x}$ & & & & & & & & & & \\
\hline Specify STR function & 1RG3 & & & & $\mathbf{x}$ & & & & & & & & \\
\hline Specify SHI function & 2RG1 & $\mathbf{x}$ & & & & & & & & & & & \\
\hline Fix kinematics & 3RG1 & $\mathbf{x}$ & $\mathbf{x}$ & 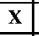 & $\mathbf{x}$ & & & & & & & & \\
\hline Fix axle spread & 4RG1 & & & \begin{tabular}{c|ccc}
$x$ \\
\end{tabular} & & & & & & & & & \\
\hline Fix Clutch Internal Control & 4RG2 & & $\mathbf{x}$ & & & & & & & & & & \\
\hline Fix lubricant & 4RG3 & & & & $\mathbf{x}$ & & & & & & & & \\
\hline Fix Gearbox architecture & 5RG1 & $\mathbf{x}$ & $\mathrm{x}$ & \begin{tabular}{|l|}
$\mathbf{x}$ \\
\end{tabular} & $\mathbf{x}$ & & & & & & & & \\
\hline $\begin{array}{l}\text { Design ACT } \\
\end{array}$ & 6RG1 & $\mathbf{x}$ & & & & $\mathbf{x}$ & & & & & & & \\
\hline Design SYN & 6RG2 & $\mathbf{x}$ & & & & & $\bar{x}$ & & & & & & \\
\hline Design IS & 6RG3 & $\mathbf{x}$ & & & & & & $\mathbf{x}$ & & & & & \\
\hline Design CLU & 6RG4 & & $\mathrm{x}$ & & & & & & $\mathbf{x}$ & & & & \\
\hline Design CI & 6RG5 & & $\mathrm{x}$ & & & & & & & $\bar{x}$ & & & \\
\hline Design D & 6RG6 & & & $x$ & & & & & & 2 & $\bar{x}$ & & \\
\hline Design IMP & 6RG7 & & & $\mathrm{x}$ & & & & & & & & $\underline{x}$ & \\
\hline Design HBX & 6RG8 & & & & $\mathbf{x}$ & & & & & & & & $\mathbf{x}$ \\
\hline Fix rolling bearings and casing & 7RG1 & & & & & & & & & & & $\frac{\bar{x}}{x}$ & \\
\hline Fix components design & 8RG1 & & & & & & & & & & & $\bar{x}$ & $\mathbf{x}$ \\
\hline $\begin{array}{l}\text { Edit integration and validation } \\
\text { document }\end{array}$ & 9RG1 & $\mathbf{x}$ & $\mathbf{x}$ & $\mathbf{x}$ & $\boldsymbol{X}$ & $\mathbf{x}$ & $\mathbf{x}$ & $\mathbf{x}$ & $\mathrm{x}$ & $\mathbf{x}$ & & & $\mathbf{x}$ \\
\hline
\end{tabular}

Fig. 3. Dependencies between robotized gearbox and design process.

design manager to establish the design process architecture. On the left side of Fig. 3, we enumerated a list of tasks included in the design process. Fig. 3 displays the mapping matrix between robotized gearbox and design process (robotized gearbox - process DMM). In the columns, we listed both functions and components as they are objects of different design tasks. We can notice that the shifting function, and consequently drivability, is linked to eight activities. The task "specify shifting function" ("2RG1") is constrained by the specification of the other system functions through the kinematics choice. This mapping matrix also reveals three sets of tasks (this note is consistent with the principles of systems engineering): functional analysis (from ORG1 to 2RG1). system architecture definition (from 3RG1 to 5RG1), and component design (from 6RG1 to 9RG1).

Fig. 4 displays the design process architecture. Partitioning algorithms could be used "for getting the DSM in an uppertriangular form at the extent possible" [29]. In fact, to obtain this list of tasks and this sequence, the MGT interviewed gearbox design experts, discussed about interfaces and deliverables, and then, streamlined the development process. The process DSM revealed that the development process had been organized according to three main stages corresponding to the three sets of tasks mentioned earlier. The level of detail proposed in this paper is sufficient to cover key design tasks and is consistent with the detail level adopted in the gearbox architecture.

The stage of system architecture definition was important to allow concurrent engineering for component design tasks and to decrease the risks of long iterations (regular technical reviews have been planned, but not represented in the process DSM). The design process architecture and project management proved to be competitive as the project duration was shorter than the target duration (120 weeks). The managers' abilities to redesign appropriate design processes contributed to the improvement of the operational performance and the compliance with the target of time to market.

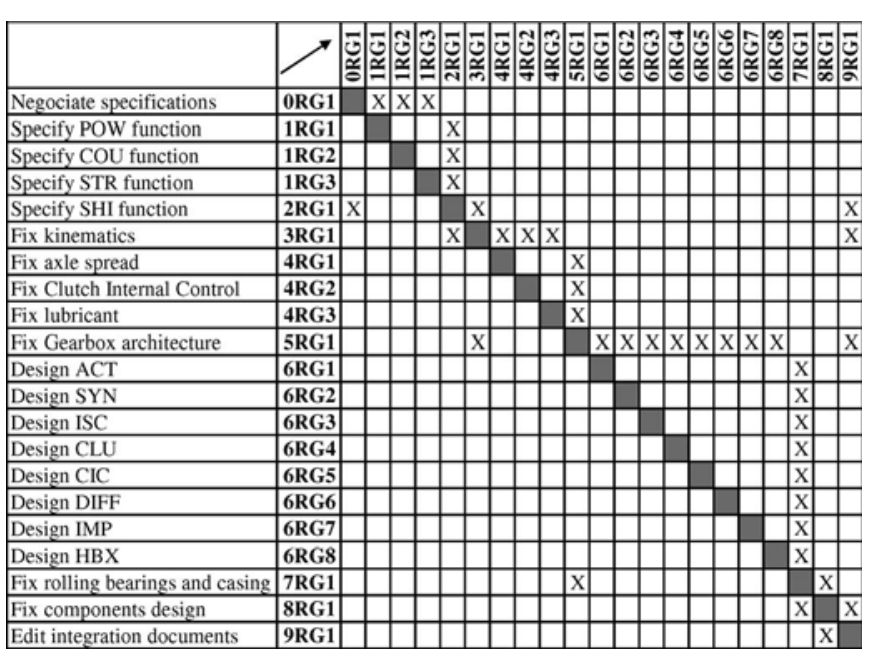

Fig. 4. Design process DSM.

\begin{tabular}{|c|c|c|c|c|c|c|c|c|c|c|c|c|c|c|}
\hline \multicolumn{2}{|l|}{ Organization DMM } & \begin{tabular}{|l|l|} 
& $\mathbf{5}$ \\
$\mathrm{y}$ & $:$ \\
\end{tabular} & & & 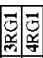 & & & & & & & & & \\
\hline \begin{tabular}{|l|} 
Project manager \\
\end{tabular} & MGT & $\mathrm{x}$ & & & $\mathbf{x}$ & & $\mathrm{x}$ & & & & & & $\mathbf{x}$ & \\
\hline Power transmission function architect & $\mathbf{A}$ & $\mathbf{x}$ & & & $\mathbf{x}$ & & & & & & & & & \\
\hline \begin{tabular}{|l|} 
Coupling function architect \\
\end{tabular} & COUA & & $\mathrm{x}$ & & & $\mathrm{x}$ & & & & & & & & \\
\hline Strength function architect & STRA & & & $\mathrm{x}$ & & $\mathrm{x}$ & & & & & & & & \\
\hline Shifl function architect & SIIIA & & & $\mathbf{x}$ & & & & & & & & & & \\
\hline Actuator devclopment leader & ACTL & & & & & & & $\mathbf{x}$ & & & & & & \\
\hline \begin{tabular}{|l|l} 
Synchronizer development leader \\
\end{tabular} & SYNL & & & & & & & $\mathbf{x}$ & & & & & & \\
\hline Internal shift control devel. leader & ISCL & & & & & & & & $\mathrm{x}$ & & & & & \\
\hline \begin{tabular}{|l|} 
Clutch development leader \\
\end{tabular} & CLUL & & & & & & & & & $\mathrm{x}$ & & & & \\
\hline Clutch internal control devel. leader & CICL & & & & & & & & & $\mathbf{x}$ & & & & \\
\hline Differential development leader & DIFL & & & & & & & & & & $\mathbf{x}$ & & & \\
\hline Internal mechanical parts devel. leader & IMPL & & & & & & & & & & $\mathbf{x}$ & $\bar{x}$ & & \\
\hline housing box development leader & HIEXL & & & & & & & & & & & $\mathbf{x}$ & & \\
\hline Simulation and Ivaluation Leader & St:L & & & & & & & & & & & & & $\mathrm{x}$ \\
\hline
\end{tabular}

Fig. 5. Organization process DMM.

3) Organizational Architecture: This design process was quite new in gearbox development projects. These changes implied the definition of new types of teams and design roles or positions. They induced the restructuring of competence-based design organizations, which developed capabilities to design functional modules.

We captured the design organization by identifying the new roles and their responsibilities, and consequently, the technical interactions between them. The left side of Fig. 5 displays the list of roles of the team members. According to the detail level adopted in the core competence analysis, operational designers do not appear in the proposed DMM in Fig. 5. This DMM is a mapping between the project tasks and the individual roles. In order to avoid conflicts, there is only one decision maker in charge of each design task, but the outsourced components were codesigned with the suppliers' teams. The organizational architecture is obtained by documenting the interactions between actors during the development project. We interviewed the MGT, the system function architects, and the component development leaders to assess the integration effort of design organizations [29]. We asked them to rate the criticality of their interactions with one another during the gearbox definition phase and the detail design phase. In the proposed method, we are interested in a qualitative evaluation only and a binary scale is sufficient. 


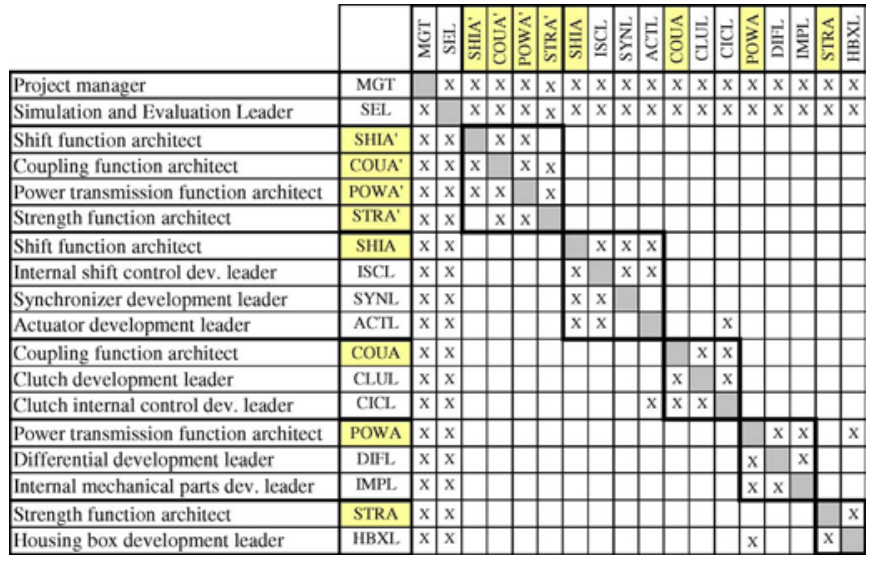

Fig. 6. Organization DSM.

Fig. 6 displays the binary organization DSM and the resulting architecture, where " $\mathrm{X}$ " means that information flows were identified between two actors. We checked the consistency of the design managers' answers and interviewed some actors again to check that they agreed with each other. We rearranged the original DSM and introduced redundant roles of function architects to highlight their key roles. This architecture was validated by the MGT.

We noticed that the MGT, and the simulation and evaluation leader (SEL) were two integrative actors. They interacted with every actor during the project. This information is consistent with the combination between the gearbox - process DMM, the process DSM, and the organization DMM. In fact, the MGT was in charge of tasks 0RG1, 3RG1, 5RG1, and 8RG1 (negotiate specifications, fix kinematics, fix gearbox architecture, fix components design, respectively). These tasks were related to the others, which were under the responsibility of all the designers. The SEL was in charge of the task 9RG1 (edit integration documents), which consisted of risk synthesis for all functions and components. Skills necessary to play these key roles were related to coordination, integration, and a thorough knowledge of mechatronic systems.

The architecture of the robotized gearbox project was complex. There was a central organization called the "system integration team," which regrouped the MGT, the system function architects (power transmission, coupling, strength, and shift function architects), and a SEL who is charge of the management of risks. This crucial team was in charge of key design stages related to functional specification, system architecture, and also system integration and requirement validation. This team developed the capability to design hybrid architectures of robotized gearboxes and the capability to integrate relatively complex systems.

Each system function architect was responsible for the integration of the functional module. She/he managed a modular development team composed of component development leaders, since his/her role was to allocate functional requirements onto concerned components. This leads us to conclude that each function architect has played an integrative role inside his modular team and an engineering liaison role between the concerned
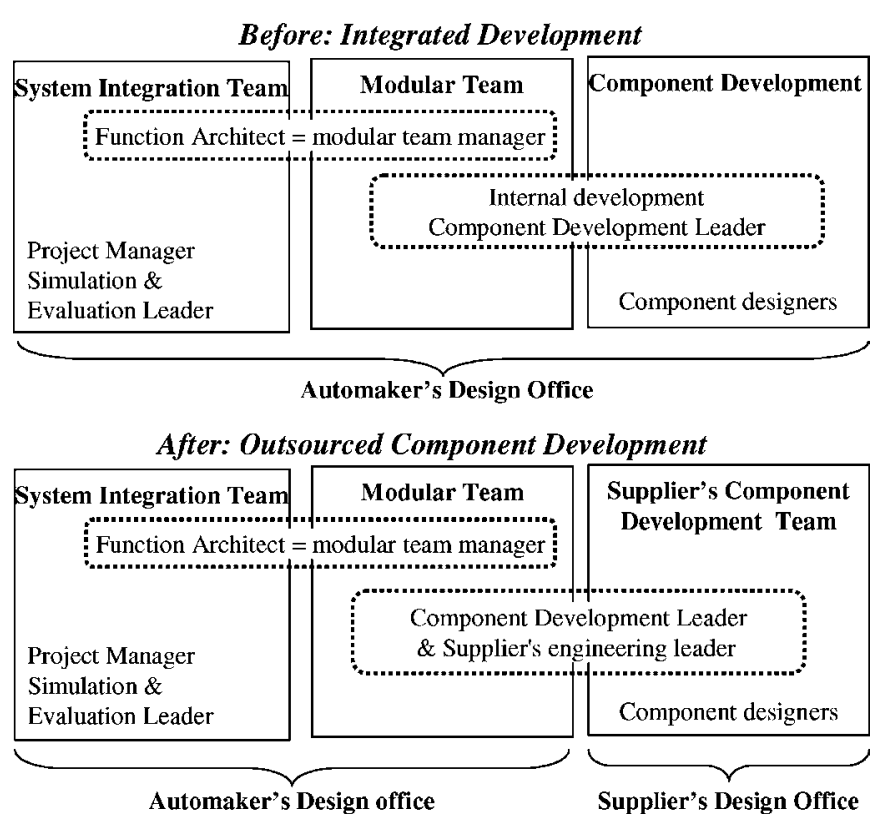

Fig. 7. Key links within organization domain.

component development teams. For instance, the actors linked to gearshifting (and then, drivability) formed a crucial modular team: shift function architect (SHIA), internal shift control development leader (ISCL), synchronizer development leader (SYNL), and actuator development leader (ACTL).

Fig. 7 is based on Fig. 6. It shows the key articulation between the automaker's design office and the supplier's one. In the new design organization, component development leaders had a double role. Firstly, they managed a subteam (a component development team). Secondly, they ensured that the collaboration with the suppliers' teams was effective. It was the case in the studied project for the outsourced components: SYN, clutch, and ACT. Concerning this last component, the ACTL was responsible for its specification and validation, its integration in the gearbox, and its adaptation in the powertrain. He led an ACT development team and played an engineering liaison role with the engineering leader of the supplier's development team. The supplier's team had to codesign gearshift strategies (cospecification of the ACT control) and was in charge of the detail design of the ACT control, electrical devices, model-based software, and its mechanical parts. The component development leaders and the suppliers' engineering leaders played a key interface role (engineering liaison, bargaining, etc.) between the teams of both the automaker and its suppliers.

4) Propagation of Requirements Through Architectures: By means of the product DSM and product-process DMM, we were able to link the distinctive requirements, i.e., drivability, fuel consumption, and reliability, to the concerned components and tasks. By continuing the propagation of the requirements "drivability" or reliability, we observed that the "gearshifting" development team developed a capability to design this key functional module that fulfils these requirements. Moreover, the "power transmission" development team was also crucial as it was concerned with the capability related to the fuel consumption 


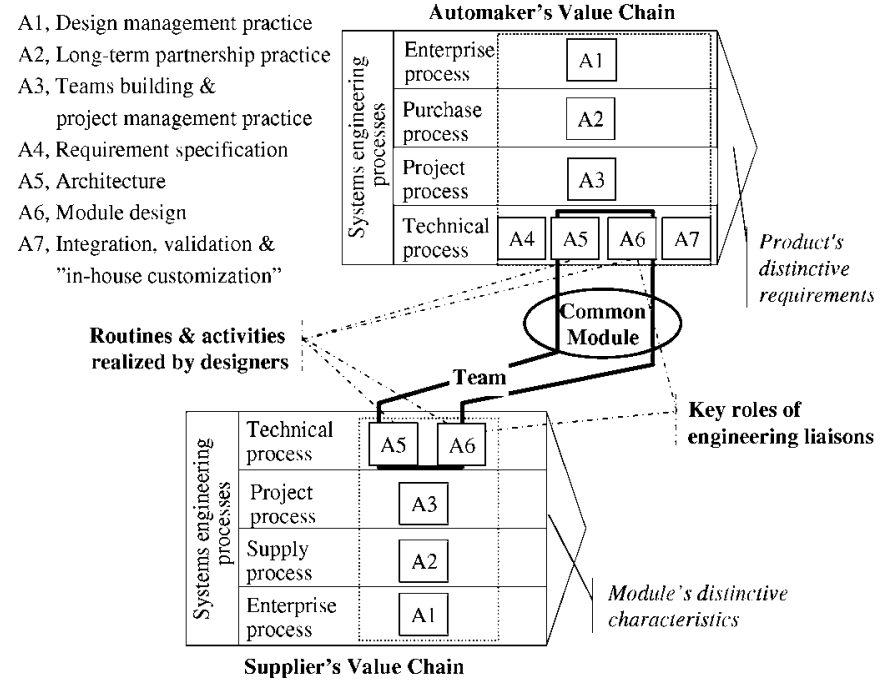

Fig. 8. Value-creating network related to powertrain design.

improvement. In this case study, we were able to associate distinctive requirements to crucial modular teams. The new organizational architecture revealed that the ACTL and the "clutch internal control" development leader (CICL) had played the key role of engineering liaison between two overlapping modules within the automaker's design office.

\section{Identification of the Gearbox Value-Creating Network}

Intrinsic complexity of the powertrain system explains why this product is codesigned by the automaker and a network of suppliers, and why managerial methods. like systems engineering ones are applied [59]. Fig. 8 represents the gearbox-related value-creating network. This figure shows that three entities ensure the cohesion of the network. The first one is the common module, which the automaker's and suppliers' designers develop. The second one is the common or compliant routines, which the automaker's and suppliers' designers have in the field of systems engineering. The last one is the key role of engineering liaisons as previously mentioned.

Gearbox development is a complex and expensive process. The role of the design managers in the car design office and their homologues in the first tier suppliers was to ensure that all the design organizations achieved their operational missions (respect of cost, quality and delay, and risks management). They also had to improve the efficiency of collaboration and crosslearning (cooperative value) by aligning their design organizations (roles of engineering liaisons) and routines. Managers involved in purchase processes had to reduce transaction costs by creating a market framework inside, which the bargaining of automaker-suppliers could be achieved as efficiently as possible.

In this case, such an organizational pattern refers to the ACT, which is a component that highly contributes to distinctive requirements of the robotized gearbox. Therefore, the automaker has selected a supplier to codesign it in the framework of a longterm partnership. The supplier had already developed core competence in designing ACTs of robotized gearboxes for Grand Tourer or F Segment cars. These competencies were comple- mentary to the car design office's ones. At the bargaining process level (purchase versus supply processes), the design managers tried to define the conditions for a long-term "win-win" partnership. The car design office and the suppliers shared a part of their management tools and practices to enhance codesign of hybrid architectures. They defined key engineering liaison roles: the ACTL (the person in charge of developing the ACT within the car design office) and the engineering leader within its supplier. Their project processes shared or developed some collaborative tools in order to virtually integrate module models in the system models (functional, behavioral, and structural models). At an operational level (technical processes), they collaborated to define the ACT control. The supplier of the ACT was strongly involved in the fulfillment of the gearshifting function. However, due to budget restrictions, the car design office temporarily hired engineers who were in charge of specifying the behavior of the ACT and codefining its control system. Hence, the design office did not leverage this project to improve its capability to develop in-house learning, which is related to the codevelopment of key mechatronic modules.

\section{E. Ex-Postevaluation of the Produced Design Capability}

Once the robotized gearbox project was finished, with the design managers, we used in a global and visual way, a qualitative criteria tree to estimate if the capability produced through the project was a core competence or not. Core design competence criteria and their qualitative values are presented in Table I. If all the values were very high, then, in the current market context, the automaker would be the leader in robotized gearboxes for B segment cars (subcompact cars). This however is not the case. It is a credible follower, but not an indisputable leader. In Table I, in the second column, the white squares indicate qualitative criteria estimated by design managers whereas the black ones are related to rough aggregative criteria. The third column corresponds to the design capabilities (identified in Part $\mathrm{B}$ or through the previous diagnosis), which contribute to the automaker's sustainable competitive advantage.

As shown in Table I, the design managers of the car design office conjectured that its external and internal values were high. A design capability in robotized gearbox development was not so common (high value for the rareness criteria linked to the provisory leadership in robotized gearboxes for B segment market cars). The hybridizing process related to the robotized gearbox project produced an efficient outcome. Thus, the system requirements were satisfied (drivability, reduction of $\mathrm{CO}_{2}$ emission, reliability, and cost). Modular teams' capabilities and function architects' roles were able to guarantee the generality of the knowledge acquired at the end of the given project (very high level of sustainability). For example, they were able to increase the level of abstraction of the functional or behavioral models used and produced by mechanical designers. Note that the embeddedness value was too low. A great part of the skills concerning the specification of the controlled behavior was fully outsourced. Thus, the expectation concerning the acquisition of capabilities in codeveloping key mechatronic modules was not satisfied. The estimated value of the "cooperative value" criteria 
TABLE I

DESIGN CORE COMPETENCE CRITERIA TREe RELATED TO THE ROBOTIZED GeArbox Project

\begin{tabular}{|c|c|c|c|c|c|}
\hline \multirow[b]{2}{*}{$\begin{array}{ll}\text { Design } & \text { Core } \\
\text { Competence } & \\
\text { Criteria } & \end{array}$} & \multicolumn{4}{|c|}{ Criterion level } & \multirow[b]{2}{*}{ Key contributions of design capabilities } \\
\hline & $\bar{\wp}$ & 产 & $\underset{\text { 竞. }}{=}$ & 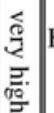 & \\
\hline $\begin{array}{l}\text { Strategic } \\
\text { Characteristic }\end{array}$ & & & - & & $\begin{array}{l}\text { Comment: this aggregated criterion } \\
\text { balances value and cost criteria. }\end{array}$ \\
\hline C1. Global Value & & & - & & \\
\hline C1.1 External Value & & & - & & $\begin{array}{l}\text { Comment: these criteria refer to market } \\
\text { and social viewpoints. They can be } \\
\text { considered as future product } \\
\text { requirements. }\end{array}$ \\
\hline C1.1.1 Rareness & & & $\square$ & & $\begin{array}{l}\text { Give a provisory leadership in the B } \\
\text { segment of the car market by improving } \\
\text { system requirements (like drivability: } \\
\text { shifting gears at less than } 250 \mathrm{~ms} \text {; } \\
\text { reliability: being as reliable as a manual } \\
\text { gearbox ; cost: being an intermediate } \\
\text { solution). }\end{array}$ \\
\hline C1.1.2 Inimitability & & & $\square$ & & $\begin{array}{l}\text { Use the same manufacturing system as } \\
\text { the one dedicated to a manual gearbox } \\
\text { once again (this capability enables } \\
\text { robotized gearboxes to be produced at a } \\
\text { competitive cost by means of } \\
\text { economies of scale) }\end{array}$ \\
\hline $\begin{array}{l}\text { C1.1.3 Regulation } \\
\text { Advance }\end{array}$ & & $\square$ & & & $\begin{array}{l}\text { Develop a line of products which are } \\
\text { more efficient than the regulation } \\
\text { requirements impose (contributing to } \\
\text { the reduction of } \mathrm{CO} 2 \text { emissions) }\end{array}$ \\
\hline $\begin{array}{ll}\text { C1.1.4 Social } \\
\text { Compliance }\end{array}$ & & $\square$ & & & $\begin{array}{l}\text { Develop a line of products which are } \\
\text { compliant with environmental values. }\end{array}$ \\
\hline C1.2 Internal Value & & & - & & $\begin{array}{l}\text { Comment: these criteria refer to the } \\
\text { automaker's and its suppliers } \\
\text { viewpoints. They are related to their } \\
\text { technological trajectory (criterion } \\
1.2 .1 \text { to } 1.2 .3 \text { ) or can be considered as } \\
\text { organizational goals }(1.2 .4 \text { to } 1.2 .7) \text {. }\end{array}$ \\
\hline $\begin{array}{l}\text { C1.2.1 Technical } \\
\text { Complexity }\end{array}$ & & & $\square$ & & $\begin{array}{l}\text { Improve the capability to design hybrid } \\
\text { architectures of mechatronic systems } \\
\text { (like robotized gearboxes). }\end{array}$ \\
\hline C1.2.2 Generality & & & & $\square$ & $\begin{array}{l}\text { Develop the capabilities of modular } \\
\text { teams, and the skills and roles of the } \\
\text { function architects }\end{array}$ \\
\hline $\begin{array}{l}\text { C1.2.3 } \\
\text { Sustainability }\end{array}$ & & & & $\square$ & $\begin{array}{l}\text { Develop model-based function design } \\
\text { practices; improve operational } \\
\text { performances of projects concerning } \\
\text { future designs of mechatronic systems. }\end{array}$ \\
\hline $\begin{array}{|ll|}\text { C1.2.4 } & \text { System } \\
\text { Integration } & \\
\text { Capability } & \\
\end{array}$ & & & $\square$ & & $\begin{array}{l}\text { Develop the capability to integrate } \\
\text { complex systems (system integration } \\
\text { teams). }\end{array}$ \\
\hline $\begin{array}{l}\text { C1.2.5 Module } \\
\text { Development } \\
\text { Capability }\end{array}$ & & $\square$ & & & $\begin{array}{l}\text { Develop the capabilities which are } \\
\text { related to the design of key functional } \\
\text { modules (gear shifting and power } \\
\text { transmission) and key engineering } \\
\text { liaison roles with suppliers. }\end{array}$ \\
\hline $\begin{array}{l}\text { C1.2.6 } \\
\text { Embeddedness }\end{array}$ & & $\square$ & & & $\begin{array}{l}\text { Develop in-house learning which are } \\
\text { related to the co-development of key } \\
\text { mechatronic modules. }\end{array}$ \\
\hline $\begin{array}{l}\text { C1.2.7 Cooperative } \\
\text { Value }\end{array}$ & & $\square$ & & & $\begin{array}{l}\text { Improve the efficiency of collaboration } \\
\text { and cross-learning with first tier } \\
\text { suppliers. }\end{array}$ \\
\hline
\end{tabular}

TABLE I

(CONTINUED)

\begin{tabular}{|l|l|l|l|l|l|}
\hline C2. Global Cost & & - & & $\begin{array}{l}\text { Comment: a design core competence is } \\
\text { supposed to be expensive to "own". }\end{array}$ \\
\hline $\begin{array}{l}\text { C2.1 Acquisition } \\
\text { Cost }\end{array}$ & & $\square$ & & $\begin{array}{l}\text { Use tools routinely related to behavioral } \\
\text { modeling and physical testing. }\end{array}$ \\
\hline $\begin{array}{l}\text { C2.2 } \\
\text { Contextualization } \\
\text { Cost }\end{array}$ & & & & $\begin{array}{l}\text { Improve the traceability of the design of } \\
\text { mechatronic subsystems but reduce as } \\
\text { much as possible the capacity of } \\
\text { competitors to imitate this design. }\end{array}$ \\
\hline $\begin{array}{l}\text { C2.3 } \\
\text { Conceptualization } \\
\text { Cost }\end{array}$ & & $\square$ & $\begin{array}{l}\text { Assimilate mechatronic concepts and } \\
\text { up to date modeling techniques. }\end{array}$ \\
\hline $\begin{array}{l}\text { C2.4 Capitalization } \\
\text { Cost }\end{array}$ & $\square$ & & $\begin{array}{l}\text { Re-use of mechatronic models and } \\
\text { design methods in another projects or } \\
\text { product lines }\end{array}$ \\
\hline
\end{tabular}

was medium as no sharing of knowledge between the car design office and its suppliers was achieved through the project. The car design office did not use this project to improve the efficiency of its collaboration and cross-learning with its ACTs' suppliers. The global cost of competence development was high, although most of the components of the gearbox were reused. We can explain this fact by the following rationale: the crucial skills needed in this kind of hybrid architecture design are system-focused (integrative), not modular-focused.

\section{DISCUSSION}

In the car design office, technological knowledge and skills were restructured in competency-based design entities (rather than functional departments), according to the key system functions of the product. This organizational architecture was aligned with the architecture of gearboxes. Each competency-based entity grouped different architects who were responsible for the same function (but involved in different projects), the concerned component development leaders, as well as the in-house component designers. In the system integration team, a function architect represented his/her competency-based entity and was responsible for the fulfillment of the concerned system function. This manager led a small team of component designers who remained in their design entity. This "lightweight project organization" [60] was justified as the interdependencies between the teams were weak at the level of the components and rather high at the function level. The function architect played a key role by developing two main kinds of skills. The first skill was orientated to the development of the team's capability. It was related to synthesis and coordination inside the team that the function architect managed. The other one concerned both the system and the partners involved in the same value-creating network. This last skill was related to integration and negotiation at the interfaces with the other teams.

Function architects had to develop their expertise related to the specification and validation of this function inside the car design office as well as possible. Otherwise, the automaker could have become strongly dependent on its suppliers. As far as the "transaction costs" theory [34] is concerned, the long-term 
TABLE II

TRAJECTORY OF THE DESIGN CORE COMPETENCE

\begin{tabular}{|c|c|c|}
\hline $\begin{array}{c}\text { Past capabilities } \\
\text { (before the presented } \\
\text { project) }\end{array}$ & $\begin{array}{l}\text { Current capabilities } \\
\text { (after the presented } \\
\text { project) }\end{array}$ & $\begin{array}{l}\text { Future capabilities } \\
\text { (expected projects) }\end{array}$ \\
\hline $\begin{array}{l}\text { Design of B segment } \\
\text { mechanical gearbox }\end{array}$ & $\begin{array}{l}\text { Design of B segment } \\
\text { robotized gearbox }\end{array}$ & $\begin{array}{l}\text { Design of B segment } \\
\text { robotized double clutch } \\
\text { gearbox }\end{array}$ \\
\hline $\begin{array}{l}\text { Past competitive } \\
\text { advantage : low cost } \\
\text { reliable gearbox }\end{array}$ & $\begin{array}{l}\text { Current competitive } \\
\text { advantage : low cost } \\
\text { reliable gearbox with a } \\
\text { high level of drivability } \\
\text { (capabilities: give a } \\
\text { provisory leadership in } \\
\text { the B segment market; } \\
\text { develop a line of } \\
\text { products) }\end{array}$ & $\begin{array}{l}\text { Expected competitive } \\
\text { advantage : higher } \\
\text { drivability than an } \\
\text { automatic gearbox for a } \\
\text { much lower price (the } \\
\text { capability to develop a } \\
\text { line of products will be } \\
\text { even more crucial to } \\
\text { reduce the costs of } \\
\text { development and } \\
\text { manufacturing) }\end{array}$ \\
\hline $\begin{array}{l}\text { Importance of the detail } \\
\text { design of the } \\
\text { mechanical parts. No } \\
\text { real system integration. } \\
\text { Gearbox integration is } \\
\text { achieved by pure } \\
\text { mechanical solutions } \\
\text { (e.g. gearbox carter). }\end{array}$ & \multicolumn{2}{|c|}{$\begin{array}{l}\text { Importance of the capability related to system } \\
\text { definition and integration at the powertrain } \\
\text { subsystem level (the whole gearbox). } \\
\text { Growing importance of the capability related to } \\
\text { system integration (supported by both mechanical } \\
\text { and software-oriented solutions) and to the design } \\
\text { of hybrid architectures. }\end{array}$} \\
\hline $\begin{array}{l}\text { Integrated design office } \\
\text { (only parts are } \\
\text { outsourced) }\end{array}$ & $\begin{array}{l}\text { Development of a } \\
\text { value-creating network } \\
\text { based on the } \\
\text { outsourcing of } \\
\text { components (like the } \\
\text { actuator) }\end{array}$ & $\begin{array}{l}\text { A value-creating network } \\
\text { based on the outsourcing } \\
\text { of modules: the ever } \\
\text { increasing importance of } \\
\text { the capability to develop } \\
\text { in-house learning related } \\
\text { to the co-development of } \\
\text { mechatronic modules }\end{array}$ \\
\hline $\begin{array}{l}\text { Empiric synthesis based } \\
\text { on realistic prototypes } \\
\text { (e.g. CAD files) }\end{array}$ & $\begin{array}{l}\text { Increase in the } \\
\text { capability to develop } \\
\text { model-based function } \\
\text { synthesis }\end{array}$ & $\begin{array}{l}\text { The more important role } \\
\text { of proof models for } \\
\text { embedded software }\end{array}$ \\
\hline $\begin{array}{l}\text { Part-focused functional } \\
\text { departments }\end{array}$ & \multicolumn{2}{|c|}{$\begin{array}{l}\text { Competency-based design entities. Increasing } \\
\text { importance of the capabilities to integrate complex } \\
\text { systems and to design key functional modules } \\
\text { (modular vs. integration teams) and key engineering } \\
\text { liaison roles with suppliers }\end{array}$} \\
\hline $\begin{array}{l}\text { Internal embodiment of } \\
\text { design core competence } \\
\text { (automaker's } \\
\text { mechanical experts own } \\
\text { the whole competence) }\end{array}$ & \multicolumn{2}{|c|}{$\begin{array}{l}\text { Long-term partnership between the value-creating } \\
\text { network's partners (the competence is shared and } \\
\text { co-developed between the automaker and its } \\
\text { suppliers). Growing importance of the capability to } \\
\text { improve the efficiency of collaboration and cross- } \\
\text { learning with first tier suppliers }\end{array}$} \\
\hline
\end{tabular}

partnership for future and more complex gearbox development projects is required.

The team in charge of the shifting module design developed a capability related to the knowledge of mechatronic engineering as this module was made of mechanical parts, ACTs, sensors, and a control system. This capability was shared between the car manufacturer and the supplier of the ACT as they cospecified the expected behavior of the robotized gearbox and covalidated the working of this module. The supplier was selected early on in the innovation phase according to its capability to be (or to become) an innovative integrator of this mechatronic component.
The team responsible for the power transmission module developed a specialized capability, i.e., thorough expertise relative to a particular function. It is similar for the designers in charge of the SYN design inside the shifting module team, since it is a mechanical component.

In this design office, the knowledge transfer between different projects was facilitated within the competency-based entities by communities of practice, which were led by a "technological leader". Moreover the system project team included functional support representatives (for instance, planning, quality, accounting, and test), which were multiproject at the same time, and then, also shared new innovative solutions throughout the gearbox development projects quickly.

Table II sums up the main changes made to the car design office's gearbox design capabilities. It shows that the acquired capabilities related to the robotized gearbox project are likely to be extended to future innovative gearboxes.

The new gearbox is a significant innovation within the B market due to cost savings in a potential future key market. Modularity is a key paradigm for architecturing project domains and facilitates the development of key design capabilities. It favors both incremental innovations and the development of the capabilities of design organizations. The main risk of the modular strategy adopted by the design office, is that a competitor may develop a radical innovation, which may cause the existing firms to lose the leading market positions. This could be the case if an automaker (or even an outsider) launches electric cars with a price comparable to the existing standard of the B segment market.

\section{CONCLUSION}

This paper presents an approach to diagnose design core competence. We outlined how to link competence-based and valuecreating network management, with matrix-based architecture models. Well-known tools in the fields of strategic management or design management were used to identify the structure (i.e., DSM) or the coupling (i.e., DMM) between three project domains (product, design process, and organization) linked to the design core competence management. These matrix-based models helped to propagate new distinctive requirements onto design organizations involved in a common value-creating network (integrated design offices, suppliers' design offices, and teams). The different types of capabilities belonging to the teams could be identified when the organizational architecture was revealed (modular, integrative, and overlapping). A core competence criteria tree was also proposed, in order to evaluate if a produced design capability following a given product development project could be considered as a core competence or not. We presented a set of criteria, which extend the set of usual ones (rareness, inimitability, and embeddedness) by adding external criteria (compliance with social values and regulation advance), internal ones (technical complexity and cooperative value), and also the global cost of the competence (acquisition, contextualization, conceptualization, and capitalization). 
The strategic management literature fails to propose a framework, which jointly evaluates the produced capabilities following a product development project and which represents its architecture (at least partially), that is to say, the way it is embedded in the value-creating network involving several independent design offices. The case study presented in this paper focused on a design office that had restructured its organization to achieve better alignment with the architecture of the complex products it develops. However, a new alignment is not sufficient to ensure the firm's sustainable competitive advantage. Design managers will have to adapt the managerial roles, practices, and strategies to better integrate the in-house design teams and the suppliers' teams into an efficient value-creating network. The proposed method will help design managers to evaluate new design organizations, to determine if the produced capability actually corresponds to a design core competency, to represent the architecture of the design organizations that embed this core competence, and then, to identify the crucial teams and managerial roles.

The case study corresponds to another experience concerning the interest of alignment in case of modular architectures. The proposed method should help researchers to study the interest of alignment in terms of core competence development and according to different product architectures, organizational boundaries, and competitive environments.

It provides researchers with a consistent framework concerning design core competence diagnosis. Our proposition could be extended to develop a global framework and recommendations concerning competency-based management of valuecreating networks. However we need to find answers to the following questions: What would be the target of the design core competence? How would the gap between the expected core competence and the current routines of existing design organizations be measured? How would the appropriate architectures be? What would be the new managerial roles and practices?

Finally, further work is envisaged. Other applications are necessary to improve the proposed method. In our approach, DMM are used in the same way as the Japanese quality function deployment (QFD) method [61]. DMM and QFD matrices (called "house of quality") can be used to deploy the choice made in one domain into another domain, from system requirements, to the product, to the design process, and ultimately to the design organizations. The similarity may be used to better formalize the approach for propagating goals or the "voice of the end user". For instance, project goals may be propagated in such a way by introducing new goals in the process domain (such as the delay reduction). The main difficulty may be explained by the fact that some core competence criteria are holistic. They cannot be easily deployed. They do not concern the components of the dependency matrices, but the overall project. For instance, market or social criteria can be considered as project goals, which all design teams must take into account and which have an impact on all subsystems, be they modular or integrative. In this paper, we were concerned with a diagnosis of core competence, and not with the specification and deployment of new core competence criteria (organization design). In an organization design phase, it may be useful to develop a QFD "house of quality" to analyze how the elements in the different project domains may contribute to the fulfillment of the core competence criteria. This tool may help the design managers to deploy strategic goals on the different project domains. However, the QFD methodology is neither focused on the architecture of each domain, nor on the coupling between modules that belong to different domains.

The case studied in this paper dealt with hybrid architecture with three clearly identified modules from functional and physical points of view. This starting point facilitated the propagation of distinctive requirements (drivability and reliability, in this paper) through organizational and design process architectures, and also in the identification of the capabilities of crucial teams. A qualitative approach is certainly sufficient to achieve a global diagnosis. The challenge is now to study the design core competence concerning a system that is "less modular". The development of propagation algorithms and tools would be useful to simulate the quantitative impacts related to the changes of the distinctive requirements in the project domains, to propagate the "voice of the end user" or to make some insights of the designers more effective [7]. In the case of an integral architecture, this propagation is obviously more difficult and would require further investigations.

\section{ACKNOWLEDGMENT}

The authors would like to thank the design managers of the automaker's design office for their fruitful collaboration. We also thank the department editor, Prof. J. Pinto, and the anonymous reviewers who suggested useful improvements in the drafts of this paper.

\section{REFERENCES}

[1] Y. Droz, "Managing core competency for corporate renewal: Towards a managerial theory of core competencies," in Core Competency-Based Strategy, A. Campbell and K. Sommers Luchs, Eds. London, U.K.: International Thomson Business Press, 1997, pp. 53-74.

[2] R. Sanchez, "Analyzing internal and competitor resources, capabilities, and management processes," in The Oxford Handbook of Strategy: A Strategy Overview and competitive Strategy, D.-O. Faulkner and A. Campbell, Eds. New York: Oxford Univ. Press, 2002, pp. 350376.

[3] J.-B. Barney, "Firm resources and sustained competitive advantage," $J$. Manage., vol. 17, no. 1, pp. 99-120, 1991

[4] T. Felin and N.-J. Foss, "Organizational routines and capabilities: Historical drift and a course-correction toward microfoundations," Scandinavian J. Manage., vol. 25, no. 2, pp. 133-145, 2009.

[5] C. McDermott and T. Coates, "Managing competencies in breakthrough product development: A comparative study of two material processing projects," IEEE Trans. Eng. Manage, vol. 54, no. 2, pp. 340-350, May 2007.

[6] D-G. Sirmon, S. Gove, and M-A. Hitt, "Resource management in dyadic competitive rivalry: The effects of resource bundling and deployment," Acad. Manage. J., vol. 51, no. 5, pp. 919-935, 2008.

[7] R. Lester and M. Piore, Innovation: The Missing Dimension. Cambridge, MA: Harvard Univ. Press, 2004.

[8] R. R. Nelson and S. G. Winter, An Evolutionary Theory of Economic Change.. Cambridge, MA: Harvard Univ. Press, 1982.

[9] S. L. Pan, G. Pan, A. J. W. Chen, and M. H. Hsieh, "The Dynamics of implementing and managing modularity of organizational routines during capability development: Insights from a process model," IEEE Trans. Eng. Manage, vol. 54, no. 4, pp. 800-813, Nov. 2007. 
[10] R. Sanchez and A. Heene, "Competence-based strategic management: Concepts and issues for theory, research, and practice," in Competencebased Strategic Management, R. Sanchez and A. Heene, Eds. New York: Wiley, pp. 3-27, 1997.

[11] M. Danilovic and T. R. Browning, "Managing complex product development projects with design structures matrices and domain mapping matrices," Int. J. Project Manage., vol. 25, pp. 300-314, 2007.

[12] A. MacCormack, J. Rusnak, and C. Baldwin. (2008). "Exploring the Duality between Product and Organizational Architectures: A Test of the Mirroring Hypothesis," Working Paper 08-039, Harward Business School, Boston, MA [Online]. Available: SSRN: http://ssrn. com/abstract= 1104745 .

[13] M. Danilovic and P. Leisner, "Analyzing core competence and core products for developing agile and adaptable corporation," presented at the Conference DSM. Munchen, D: 16-17, Oct. 2007.

[14] R. Gulati and S. Eppinger, "The coupling of product architecture and organizational structure decisions," MIT Sloan Working Paper no. 3906. Cambridge, MA, 1996.

[15] B. Oosterman, "Improving product development projects by matching product architecture and organization," Ph.D. thesis. Gröningen Univ., Gröningen, NL, 2001.

[16] M. E. Sosa, S. D. Eppinger, and C. M. Rowles, "The misalignment of product architecture and organizational structure in complex product development," Manage. Sci., vol. 50, no. 12, pp. 1674-1689, 2004

[17] P. Kothandaraman and D. T. Wilson, "The Future of competition: Valuecreating networks," Ind. Marketing Manage., vol. 30, no. 4, pp. 379-389, 2001

[18] R. Lamming, T. Johnsen, J. Zhurong, and C. Harland, "An initial classification of supply networks," Int. J. Oper. Prod. Manage., vol. 20, no. 6, pp. 675-691, 2000.

[19] J. McGee, "Strategy as orchestrating knowledge," in Images of Strategy, S. Cummings D. Wilson Eds. Malden, MA: Blackwell, pp. 136-163, 2005.

[20] Y-K. Ro, J. K. Liker, and S. K. Fixson, "Modularity as a strategy for supply chain coordination: The case of U.S. auto," IEEE Trans. Eng. Manage., vol. 54, no. 1, pp. 172-189, Feb. 2007.

[21] G. Hamel and C. K. Prahalad, Competing for the Future. Cambridge, MA: Harvard Business School Press, 1994.

[22] K. Haafez, Y. Zhang, and N. Malak, "Core competence for sustainable competitive advantage: A structured methodology for identifying core competence," IEEE Trans. Eng. Manage., vol. 49, no. 1, pp. 28-35, Feb. 2002

[23] G. Pépiot, N. Cheikhrouhou, J-M. Furbringer, and R. Glardon, "A fuzzy approach for the evaluation of competences," I. J. Prod. Econ., vol. 112, pp. 336-353, 2008.

[24] C.-M. Christensen, The Innovator's Dilemma: The Revolutionary Book That will Change the Way You Do Business. New York, NY: Harper Collins, 2003.

[25] C. Haskins, Systems Engineering Handbook. A Guide for System Life Cycle Processes and Activities, International Council on Systems Engineering (INCOSE)-TP-2003-002-03.1. Seattle, WA. 2007.

[26] H.-A. Simon, The Sciences of the Artificial. Cambridge, MA: MIT Press, 1997.

[27] K-T. Ulrich, "The role of product architecture in the manufacturing firm," Res. Policy, vol. 24, pp. 419-440, 1995.

[28] C.-Y. Baldwin and K-B. Clark, Design Rules: The Power of Modularity Design. Cambridge, MA: MIT Press, 2000.

[29] T.-R. Browning, "Applying the design structure matrix to system decomposition and integration problems: A review and new directions," IEEE Trans. Eng. Manage, vol. 48, no. 3, pp. 292-306, Aug. 2001

[30] N. Suh, Principles of Design. Cambridge, U.K.: Oxford Univ. Press, 1990.

[31] J. Jiao, T. Simpson, and Z. Siddique, "Product family design and platformbased product development: A state-of-the-art review," J. Intell. Manuf., vol. 18, no. 1, pp. 5-29, 2007.

[32] R. Sanchez, "Modular architectures, knowledge assets and organisational learning: New management processes for product creation," Int. J. Technol. Manage., vol. 19, no. 6, pp. 610-629, 2000.

[33] R. Balachandra, Modular design and technological innovation: The case of the hard disk drives. Rep. 2002-02, The Inf. Storage Ind. Center, Univ. California, 2002

[34] O.-E. Williamson, The Economic Institutions of Capitalism: Firms, Markets, Relational Contracting. $\quad$ New York: The Free Press, 1985.
[35] M. E. Sosa, S. D. Eppinger, and C. Rowles, "Designing modular and integrative systems, presented at the ASME 2000 Int. Des. Eng. Tech. Conf. (DETC) Baltimore, MD.

[36] M. E. Sosa, S. D. Eppinger, and C. Rowles, "Identifying modular and integrative systems and their impact on design team interactions," Trans. ASME J. Mech. Des., vol. 125, pp. 240-252, 2003.

[37] K. R. McCord and S. D. Eppinger, "Managing the integration problem in Concurrent Engineering," MIT Sloan School of Management Working Paper no. 3594. Cambridge, MA, 1993.

[38] T. R. Browning, "Designing system development projects for organizational integration," Syst. Eng., vol. 2, no. 4, pp. 217-225, 1999.

[39] S. D. Eppinger and V. Salminen, "Patterns of product development interactions," in Proc. Int. Conf. Eng. Des. ICED), Glasgow, U.K., Aug. 21-23, 2001, vol. 1, pp. 283-290.

[40] K. T. Ulrich and S.D. Eppinger, Product Design and Development. New York: McGraw Hill, 2000.

[41] R. I. Whitfield, J. S. Smith, and A. H. B. Duffy, "Identifying component modules," in Proc. 7th Int. Conf. Artif. Intell. Des. (AID), Cambridge, U.K., 15-17 Jul. 2002, pp. 571-592.

[42] T. U. Pimmler and S. D. Eppinger, "Integration analysis of product decompositions," in Proc. ASME Des. Theory Method Conf. (DTM 1994), vol. 68 , pp. 343-351.

[43] P. J. Clarkson, C. S. Simons, and C.M. Eckert, "Predicting change propagation in complex design," ASME J. Mech. Des., vol. 126, no. 5, pp. 765-797, 2004

[44] J. Malmqvist, "A classification of matrix based methods for product modelling," presented at the Design 2002, Cavtat-Dubrovnik, Croatia.

[45] S. J. Chen and L. Lin, "Decomposition of interdependent task group for concurrent Engineering," Comput. Ind. Eng., vol. 44, pp. 435-459, 2003.

[46] M. Danilovic and T. Browning, "A formal approach for domain mapping matrices (DMM) to complement design structuring matrices (DSM)," presented at the 6th Int. Des. Struct. Matrix (DSM) Workshop, Cambridge, U.K., Sep. 12-14, 2004

[47] E. Bonjour, S. Deniaud, M. Dulmet, and G. Harmel, "A fuzzy method for propagating functional architecture constraints to physical architecture," Trans. ASME, J. Mech. Des, vol. 131, no. 6, pp. 061002-1-061002-11, Jun. 2009.

[48] R. P. Steward and V. Donald, "The Design Structure System: A method for managing the design of complex systems," IEEE Trans. Eng. Manage, vol. EM-28, no. 3, pp. 71-74, Aug. 1981.

[49] A. Yassine and D. Braha, "Complex concurrent engineering and Design Structure Matrix method," Concurr. Eng.: Res. Appl., vol. 11, no. 3, pp. 165-176, 2003.

[50] T. R. Browning and S. D. Eppinger, "Modeling impacts of process architecture on cost and schedule risk in product development," IEEE Trans. Eng. Manage., vol. 49, no. 4, pp. 428-442, Nov. 2002.

[51] S. D. Eppinger, R. S. Whitney, and D. Gebala, "A model-based method for organizing tasks in product development," Res. Eng. Des., vol. 6, no. 1, pp. 1-13, 1994.

[52] U. Lindemann, "A vision to overcome chaotic "design for X" processes in early phases," presented at the Int. Conf. Eng. Des. (ICED), Paris, 28-31 Aug. 2007.

[53] X. Boucher, E. Bonjour, and B. Grabot, "Formalisation and use of competences for industrial performance optimisation: A survey," Comput. Ind., vol. 58, no. 2, pp. 98-117, 2007.

[54] C.-H. Fine, Clockspeed: Winning Industry Control in the Age of Temporary Advantage. Reading, MA: Perseus Books, 1998.

[55] (2001). Object Management Group, OMG Unified Modeling Language Specification, v1.4 (OMG, September 2001). [Online]. Available: http://www.uml.org.

[56] P.-H. Hsieh, C. S. Mishra, and D. H. Gobeli, "The return on R\&D versus capital expenditures in pharmaceutical and chemical industries," IEEE Trans. Eng. Manage, vol. 50, no. 2, pp. 141-150, May 2003.

[57] T. Ohno, Toyota Production System: Beyond Large-Scale Production. Cambridge, MA: Productivity Press, 1988.

[58] S. J. Gould, The Structure of Evolutionary Theory. Cambridge, MA: Harvard Univ. Press, 2002.

[59] H. Proff, "A competence-based approach to understanding the orchestration of value chains in the development of "new" value architectures," Adv. Appl. Bus. Strategy, vol. 11, pp. 93-115, 2008.

[60] C. Wheelwright and K. B. Clark, Revolutionizing Product Development: Quantum Leaps in Speed, Efficiency, and Quality. New York: The Free Press, 1992

[61] Y. Akao, Quality Function Deployment, QFD - Integrating Customer Requirements into Product Design. Cambridge, MA: Productivity Press, 1990. 


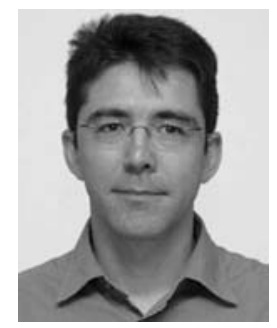

Éric Bonjour received the M.S. (Engineer) degree in mechanical engineering from the Engineering Institute of Besancon (ENSMM), France, in 1993 and the Ph.D. degree in automation from the University of Besançon, France, in 1996.

$\mathrm{He}$ is currently an Associate Professor with the University of Franche-Comté (UFC), Besançon, France. For six years, he has led a research project in collaboration with a French car manufacturer in the field of project management, competence management, and systems engineering. He has published more than 40 papers for journals, such as the Journal of Mechanical Design, the Computers in Industry, and the International Journal of Product Development, and conferences.

Prof. Bonjour is a member of International Council on Systems Engineering (INCOSE) and has been leading a Technical Committee of the Assimilated French INCOSE Chapter (Association Française d'Ingénierie Système).

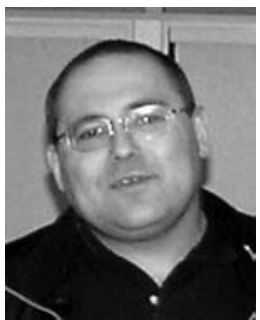

Jean-Pierre Micaëlli received the Ph.D. degree in economics, in 1994.

He is currently an Associate Professor in industrial management with the Institut National des Sciences Appliquées Lyon, University of Lyon, Villeurbanne Cedex, France. He has been engaged in several collaborative research projects with automakers, automotive suppliers, aircraft manufacturers, and engineering firms. His current research includes developing new applications in the field of computer-aided evaluation in design. He has published six books and more than 30 papers for books, journals, and conferences. 


\title{
Design Core Competence Diagnosis: A Case From the Automotive Industry
}

\author{
Éric Bonjour and Jean-Pierre Micaëlli
}

\begin{abstract}
-1990's have been marked by significant changes both in the strategic management field, with the development of competence-based management and the use of the concept of valuecreating network, and in the design management field, with the diffusion of matrix-based tools that help to manage the interdependencies between three domains of design projects: product, process, and organization. Few researchers have helped to link these two fields. However, design managers need to use these fields closely together in order to enhance the firm's sustainable competitiveness. Indeed specialists of engineering management have already underlined that design organizations are responsible for the development of lines of products that have to satisfy distinctive stakeholders' requirements. Thus, design organizations strongly contribute to the firm's core competence. In this paper, we outline a method for diagnosing design core competence. We intend to couple strategic management concepts and design management concepts to represent and evaluate design core competence in relation to the product, process, and organizational architectures. The proposed method aims to highlight crucial design organizations, which should require particular managerial attention. The method has been researched and constructed in collaboration with a car design office, and applied in the case of a new robotized gearbox design.
\end{abstract}

Index Terms-Corporate core competence, design structure matrix (DSM), organization design, project and R\&D management, project teams.

\section{INTRODUCTION}

$\mathbf{F}$ OR a long time, managers and researchers in strategic management have admitted that brands, patents, and more generally, product innovations are key variables to distinguish a firm from its competitors. But the last two decades have been marked by significant conceptual changes in their way of thinking [1]. They wish "to open the "black box" of the firm to investigate what distinguishes firms internally from each other" [2]. Leading firms own rare, specific, inimitable assets [3], "tacit" knowledge or capabilities [4], or core competences, which enable

Manuscript received April 21, 2008; revised August 8, 2008, January 1, 2009, May 14, 2009, July 17, 2009, and September 2, 2009. Review of this manuscript was arranged by Department Editor J. K Pinto.

É. Bonjour is with the Department of Automatic Control and MicroMechatronic Systems, Franche-Comté Electronique Mécanique Thermique et Optique - Sciences et Technologies (FEMTO-ST) Institute, University of Franche-Comté (UFC)/Ecole Natioanle Supérieure de Mécanique et des Microtechniques (ENSMM)/University of Technology of BelfortMontbéliard (UTBM), Unités Mixtes de Recherche (UMR) Centre National de la Recherche Scientifique (CNRS) 6174, Besançon 25000, France (e-mail: eric.bonjour@ens2m.fr).

J.-P. Micaëlli is with the STOICA Research Team, Institut National des Sciences Appliquées Lyon, University of Lyon, Villeurbanne Cedex 69621, France (e-mail: jean-pierre.micaelli@insa-lyon.fr).

Color versions of one or more of the figures in this paper are available online at http://ieeexplore.ieee.org.

Digital Object Identifier 10.1109/TEM.2009.2036838 them to build and sustain their competitive advantage when their competitors cannot do so [5]. One recommends that these firms focus on these assets, capabilities or competences in order to "bundle" them, to "deploy" them, to "leverage" them [6], and outsource all their noncore activities [7]. Such a "make or buy" recommendation is sensible because the identification of corporate core competence is rather difficult. Corporate core competence has both holistic and evolutionary properties. As a holistic concept, it refers both to capabilities of a set of organizations (offices, departments, skill networks, teams, etc.) and to the nature of the "routines" [8]. Routines correspond to the ways in which the actors who are integrated in the so-called organizations collectively do something (cooperation, coordination, bargaining, collective learning, etc.) [8], [9]. Moreover, corporate core competence is not a well-defined fixed asset, contrary to what the resource-based view might suggest [3], [6]. The scope and the content of a given core competence are continuously modified by not only market, organizational or technological threats, or opportunities [5], but also by organizational learning.

The issue concerning the identification, evaluation, and building of corporate core competence [9], [10] continues to open promising ways for researchers and practitioners [6]. In this paper, we shall not address this issue from a general viewpoint, but from a specific one focused on design. Our purpose will be to show how to make the concept of core competence operational in the specific field of design. This focus on design can be explained easily.

Firstly, this activity strongly contributes to the product's competitiveness and to the firm's sustainable competitiveness (that is to say, the whole corporate core competence). Design core competence refers to the fact that the capabilities of design organizations (teams, departments, offices within the manufacturers, and their suppliers) significantly contribute to the development of corporate core competence. Design organizations can be considered as networks of actors (teams, designers, and managers), whose skills and routines concern the way, they develop new products, composed of interdependent components (structured by a product architecture), coordinate their interdependent tasks (structured by a process architecture), and exchange information (structured by an organizational architecture). Note that the terms "structure" and "architecture" are considered as being interchangeable throughout this paper. However, to be consistent, we use more particularly the terms: product architecture, process architecture, and organizational architecture. These terms have already been used by specialists of engineering management [11], [12]. Briefly, architecture corresponds to a designable and manageable set of elements (components, tasks, and actors) and the ways in which these elements interact. 
Secondly, the scope of the design core competence that each design manager takes into account is a complex system that should be identified, analyzed, evaluated, and rebuilt [13]-[16]. These last activities require close collaboration among the different design managers (program manager, product development manager, system architect, project manager (MGT), etc.). The quite recent "competence movement" [10] does not offer mature managerial tools to support these activities, because of the intrinsic complexity of its object.

In this paper, we do not intend to meet all the competencefocused needs of the design managers, but rather to propose an approach for identifying the structure and diagnosing design core competence in relation to models concerning organizational, process, and product architectures. As suggest some strategic management theorists [6], we shall apply this approach in a particular context, i.e., the complex automotive design organized according to the principles of systems engineering and involving the design offices of both the automaker and its suppliers. All these organizations are part of a "value-creating network" [17], that is to say, a design organization involving several independent firms, which contribute to a global value chain by coordinating their own value chains and design processes, making their activities more cooperative, offering a mutual "operational assistance" [18], and sharing their development costs, resources, practices, data, knowledge, and innovation projects. Thus, an organizational equilibrium is obtained between the contributions and retributions of the automaker and its suppliers. In the specific case of the automotive industry, the outcome of such a value-creating network is either the whole car or one of its main subsystems: body, passenger compartment, cockpit, electric network, powertrain system, etc. An automotive valuecreating network integrates within common projects and teams the automaker as an "orchestrator" [19] and a set of "module suppliers" (first tier supplier), and possibly tier 2 down to tier $n$ suppliers also [20]. Finally, design core competence is not a bundle or a bulk of designers' skills, and design organizations' capabilities and routines. We aim to show that it is convenient to use well-known engineering tools like dependency matrices [design structure matrix (DSM) and domain mapping matrix (DMM)] to represent the architecture of a design core competence, and to highlight crucial design organizations and key roles.

The remainder of this paper is structured as follows. Section II develops a brief literature review of the concepts, we propose and are used in the method. Section III presents the method, which helps to represent the structure and to evaluate design core competence. Section IV describes its application in the case of the development of a robotized gearbox, and finally, Section V discusses the results obtained.

\section{LITERATURE REVIEW}

This section sums up the research related to the design core competence management. It also presents the global concept of corporate core competence, the principles of systems engineering, and the matrix-based models related to product, process, and organizational architectures. Finally, it points out existing and missing links between research related to core competence management and other research fields concerning product architecture and design organization.

\section{A. From Corporate to Design Core Competence}

In management literature, the concept of corporate core competence has been used, since the 1990's to understand internal and particular factors, which explain the firm's differentiation and specialization [1], [6], [7], [21]. Strategic management researchers have tried to distinguish between the concept of core competence and those of asset, skill, routine, and capability [4], [5]. A consensus appears between them. Thus, functionally, corporate core competence is a "dynamic capability" [8], which produces an expected sustainable competitive advantage and plays a key role as a "gateway to tomorrow's markets" [21]. It does not refer to the firm's routines or capabilities, which are related to a particular current product. It concerns the distinctive future line of products, which the firm intends to design, manufacture, and sell. This line of products can strengthen the firm's position on the market or enable its diversification by creating a leading position in a new market. Corporate core competence is then a future and product lineoriented concept. Researchers have proposed a set of strategic criteria, which is useful to establish if an identified capability can be considered as a corporate core competence or not. This aspect has been greatly documented in literature, probably because it allows well-known multicriteria decision methods to be used, e.g., scoring or diagnosis tools [22], [23]. The criteria used to discriminate a corporate core competence depend on the evaluator's viewpoint. For an external evaluator (customer, competitor, supplier, researcher, etc.), core competence value refers to its rareness, its inimitability, and its nonsubstitutability [1], [3], [5], [6], [10], [21], [22]. From this point of view, the concept of core competence is very close to that of resource. For an internal evaluator (design manager, designer, etc.), core competence value also depends on three main inducers.

1) Its tacit and contingent nature.

2) Its generality. A core competence can be replicated. It can be reused from one product [5], design organization, or project to another.

3) Its compliance with the other bargaining, managerial or technological routines, and the capabilities the firm has already developed.

At the most elementary level, design core competences are embedded in the designers and design managers who are involved in design organizations. These actors and organizations contribute to the firm's sustainable competitive advantage because of following.

1) Insight into their customers' future values, needs or expectations [7], [21].

2) Knowledge about weaknesses and strengths of rival firms, and the technologies the firm (or its industry) [6] has adopted and assimilated.

3) Knowledge about technological opportunities.

4) Dynamic capabilities to create in time, new lines of products; 
5) Operational capabilities to improve the design processes' efficiency (delay, cost, quality, risk management, etc.).

Dynamic capabilities can produce incremental or "sustaining” [24] innovations that improve existing solutions by adding new functionalities, modifying architecture, human-machine interface, or form design, etc. They can also induce a main change in the firm's technological trajectory if they suppose the removal of the technological and organizational barriers [7]. It is the case when the firm hybridizes scattered technologies (radio and telephone in the case of mobile phones) [7] or explores new product lines (polyvalent electrical cars instead of classical cars with a thermal engine) [5].

Moreover, researchers link the sustainable competitive advantage induced by the corporate core competence to a value chain [7]. Therefore, the corporate core competence is considered as the set of activities, which must be internalized. However, this approach is too global [6]. It does not specify, which aspects of the design activity effectively contribute to the firm's sustainable competitive advantage: Are they linked to the fulfillment of distinctive requirements concerning the line of products? To the capabilities of the design organizations? To the process and organizational architectures, which combine the design capabilities? It is worth noting that despite its importance, little research has examined how the organizational architectures embody the design core competence.

\section{B. Systems Engineering}

Since the 1990's, the number of the systems engineering standards has grown to enable clients and contractors to master the development of systems, which are more and more complex. We can mention, without being exhaustive: MIL STD 499, EIA-ANSI 632, IEEE 1220, and ISO 15288. To put it briefly, the purpose of systems engineering is to organize complex design, so that the designed system achieves all the environmental and stakeholders' requirements, which are related to its entire life cycle. Systems engineering is clearly focused on both products and design processes. System complexity when taken into account by promoters of systems engineering induces at least three consequences.

1) Its development requires the decomposition into different interrelated modules (modularization) and layers (stratification).

2) At each layer, the design process is organized according to a clear division and coordination of different types of processes: bargaining (agreement or purchase versus offer), managerial (project or team management, etc.), support (prototyping, tests, etc.), and technical (system definition, functional analysis, architecture, system integration, etc.). Design teams are involved in the technical process, which is a sequence of activities that may be represented by the "V-cycle model" [25], a top-down approach (specification and design) followed by a bottom-up one (integration and validation).

3) The holistic stages, which concern system definition, architecture, and integration, are crucial.

Architecture and integration are required when designers have to cope with a high level of complexity [26]. Thus, architecture is not only a set of interrelated elements (internal view), but also an entity that integrates elements to satisfy all the requirements (external view). In the case of the architecture of a complex system, there is no trivial relation between the list of requirements and the set of components, and it is necessary to cluster them, in order to assign comprehensible and manageable work packages (or building blocks) to design teams. Systems engineering principles help the system architect to create subsystems according to a design process that can be decomposed into design tasks. These tasks are carried out by design organizations, and are then, supported by their capabilities [4], [8]. The integration of all the capabilities of the organizations is carried out to produce the whole design core competency.

\section{Architecture Design}

As mentioned earlier, the systems engineering framework is mainly related to product, design process, and organization. Thus, in the early phase of system definition, design managers and system architects have to jointly define the preliminary architecture of the product, and the architectures of the design process and organization [14].

1) Product Architecture: Ulrich defines product architecture as "the scheme by which the function of a product is allocated to physical components" [27]. According to this author, product architecture consists of following.

1) The arrangement of functional elements, or the function structure.

2) The mapping from functional elements to physical components.

3) The specification of the interfaces between components.

A key issue concerning product architecture is how to define the concept of module. Fortunately, there is a common way of defining it by only focusing on interactions between elements [28]. In addition, Browning defines "integrative elements" as interacting with all of the modules without belonging to a module [29].

Another key point concerning product architecture is the degree to which it is modular or integral. In modular architectures, the functions of the product map its physical components oneto-one, following Suh's "uncoupled design" principles [30]. At the other extreme, in "integral architectures", several product functions are linked to a single component or a small number of components. Consequently, system architects define modular product architectures with the following purposes.

1) Economies of scale (reusability of solutions from a product or project to another one) and economies of scope (production of a wide product family [31] or line by combining low-cost modules, which are specialized and even mass-produced [9]).

2) Organizational learning. Greater clarity in targeting useful organizational learning at both intra and intermodular levels [32] (specialized and integrative learning) is enabled by modular architectures.

3) A controlled introduction of new and risky solutions [33].

4) A minimization of the "transaction costs" [34]. Modularization reduces the bargaining expenses. It helps to precisely define the requirements of the module, which 
each team has to satisfy. It also reduces coordination efforts among design organizations involved in a common project.

From an "analytical perspective" [7], a modular architecture may be an ideal pattern. But in real design situations, designers have to make a tradeoff between modular and integral architectures [35].

2) Architectures of the Design Process and Organization: Architecture refers not only to product, but also to organization design. Thus, the functional view of the organization corresponds to the development process that has to meet the goals of the project. This process is decomposed into tasks. The concrete view corresponds to all the teams, which make up the global design organization (internal or suppliers' design teams), and which may be decomposed into smaller design organizations and individual designers. Key managerial decisions concern the allocation of design teams to the design tasks. The teams are in charge of carrying out the assigned tasks.

In complex product development projects using the principles of systems engineering, several teams develop the components, the modules or subsystems, and work to integrate all of these components to create the final product. Sosa, Eppinger, and Rowles, call "modular teams" those, which design modular systems, and "integrative teams" those, which design integrative systems [36], [37]. Browning suggests that "integrated product teams" bring cross-functional members together to achieve the development of particular subsystems or system components [38]. He adds that different levels of system teams may be required in the case of large projects. System teams may be split up into subsystems teams, components teams, and functional support groups. It is worth noting that the capabilities of modular teams are usually more specialized than those of integrative teams. However, if a team has to design a mechatronic module (or subsystem), then the adjective specialized does not refer to a single well-known discipline (mechanics, hydraulic, etc.), but rather to a coherent core of several disciplines required by the design of the multiphysical module.

3) Matrix-based Architecture Models: Matrix-based architecture models provide useful representations of internal and external interactions (or dependencies), which link three project domains: product, design process, and design organization [39]. They are increasingly being used, as they are able to support different research goals, for example, product modularization [40], [41], analysis of technical interactions either within the products [42] or within the project organization [35], and change propagation analysis [43]. In fact, there are two subtypes of dependency matrices [44].

1) Interdomains matrices, which represent dependencies between two domains. These matrices are called incidence matrices [45], traceability, and allocation matrices (IEEE Std 1220, 2005) or DMM [46]. They have to ensure the cohesion between the product subdomains [47] and more generally, between project domains [11].

2) Intradomain matrices, which represent dependencies between elements within the same domain, e.g., between components. These matrices are usually called DSM [29], [37], [48].
DSM are now popular modeling and analysis tools, especially for purposes of decomposition and integration as they display the relationships between elements of a system in a compact and visual format [42]. Thus, they are used to identify projectdomain architectures (for a literature review, see [29]): the product architecture, the architecture of the design process [49]-[51], and the organizational architecture, which corresponds to the decomposition of the projects into different teams or communities [35], [45].

A few researchers recently proposed to combine several DSM and the connecting DMM [11], [46], [47], [52] in order to link multiple domains, thus creating a multiple domain matrix (MDM). Danilovic and Leisner use DMM to link important module areas (which compose end product architecture) and existing design skill areas [13]. Their aim is to identify and align crucial skill areas related to major module areas (a set of modules relatively homogeneous from a competence perspective).

\section{Synthesis}

A recent review concerning competence management underlines the need for models and tools, which help managers to make competence-based management more effective by linking operational and strategic decisions [53]. As mentioned in the previous part, in the field of strategic management, some concepts help to identify or evaluate core competencies. In the field of design management, matrix-based architecture models can represent the architectures of the product, process, and organization. Little work has helped to link these two fields. However, design managers and systems architects who are responsible for the development of complex products need to combine them very closely. Modularization is considered as a valuable way for defining modules as common objects of value-creating networks [20] and for facilitating the development of capabilities based on modular organizational routines [9]. A few researchers have recommended that the product architecture should appropriately mirror (or align, match) the architecture of design organizations, and thus, the value-creating network that develops it [12], [14]-[16], [39], [54].

Design managers could use DMM and DSM to identify areas, where a value-creating network could be built in order to exploit identified internal, addressed, and outsourced design core competencies. Thus, the scope of dependency matrices should be extended, from an "analytical perspective" [7] and an operational content to a strategic one. DSM or DMM must not be considered only as formal models although they may be rearranged by clustering or sequencing algorithms separately. The combination of dependency matrices must be considered as a managerial tool, not as an optimization method only. Our purpose is not to answer the following question: How to modularize product and define efficient design organizations? But rather, how to use dependency matrices to represent the architecture of design core competence? In this paper, we propose their use to give a static architecture of design core competency. Such representations are helpful and provide a common language for design managers and system architects. The questions we have mentioned earlier are very general. In the remainder of this 


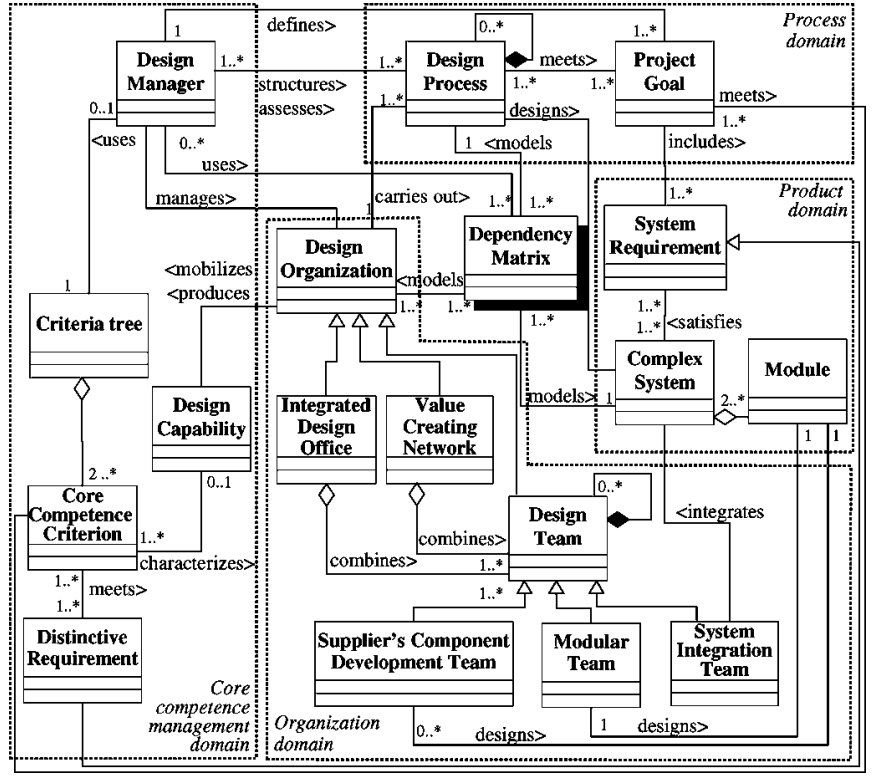

Fig. 1. Design core competence framework.

paper, we focus on the design of powertrains relying on complex architectures, developed by integrated product teams.

\section{Approach to DiAgnose Design CoRe COMPETENCE}

In this section, we briefly present an approach for identifying the architecture and evaluating global design core competence in the case of complex products. Firstly, we present key concepts of competence-based design management and secondly, we outline the proposed method for diagnosing design core competence.

\section{A. Conceptual Framework}

The conceptual framework we propose intends to represent the links between key concepts involved in the building of design core competence. These concepts refer to the capabilities of the design organizations and to the criteria used to appreciate if the capability of the global design organization is a core competence or not. This framework is presented by means of the unified modeling language (UML) class diagram in Fig. 1 [55]. Dependency matrices play the role of interconnecting models (in the center of the figure). Dependency matrices are seen as useful tools to model the architectures of product, design process, and organization along with their interdependencies. Thus, Fig. 1 integrates around the class called "dependency matrix" several domains related to product, design process, organization, and core competence management.

Product domain: The designed complex system has to satisfy system requirements and is decomposed into several modules.

Design process domain: The design process is organized and assessed by a design manager. It may be decomposed into tasks and has to meet the project goals.

Organization domain: Design organizations (integrated design office, value-creating network, and design teams) carry out design processes and tasks. They are organized, coached, evaluated, and represented by a design manager (system architect,
MGT, team manager, etc.). Design teams may be decomposed into smaller design teams. A system integration team is responsible for integrating the complex system whereas in-house modular teams and teams within the suppliers' design offices are in charge of developing modules and components.

Core competence domain: This domain integrates the concepts (distinctive requirement, design capability) and the tools (core competence criterion and criteria tree) used by design managers. Distinctive requirements and project goals have to meet the corresponding core competence criteria so as to judge if the final project outcome is successful or not. Design managers can use a criteria tree composed of core competence criteria to evaluate if the produced design capability is a core competence or not.

Firstly, this tree combines several criteria related to the value of the core competence estimated by an external or internal evaluator. Potential criteria are identified between brackets next. In the former case (external view), the focus is on market criteria (rareness and inimitability of the competence under evaluation) [3] or social criteria (its regulation advance and its social compliance). In the latter case (internal view), other criteria add new branches to the criteria tree. They are related to the effects of the evaluated capability on the leading firm's and suppliers' new routines. Does it help to increase the complexity of the outcome of the design activity (criterion: technical complexity)? Is it really sustainable and related to a perennial product line (criteria: generality and sustainability) [3]? Does it help the suppliers involved in the value-creating network to carry out the development of a whole "design module" efficiently [20]? Does it enhance long-term efficiency of the teams in charge of the module development and system integration (criteria: system integration capability or module development capability)? Is it easy to understand and to replicate for a competitor who wants to create a similar value-creating network (criterion: embeddedness)? Does it enhance cross-learning with first tier suppliers (criterion: cooperative value)?

Secondly, the value criteria related to design core competence are balanced with cost criteria. The main idea is easy to understand. The development of design capabilities, which support design core competence is an expensive process, which induces a global cost [3], [56]. The new capability can be supported by new purchased assets or newly hired experts or managers (criterion: acquisition cost). The context concerning the production of the new capability has to be remembered, understood, and explained (criterion: contextualization cost). One has to make the related knowledge explicit by using design models and knowledge management models (criterion: conceptualization cost). Last but not least, this conceptualized knowledge has to be capitalized in order to make its diffusion and its sustainability effective (criterion: capitalization cost). Fortunately, the more expensive this process is, the higher the barrier to entry related to the evaluated design capability is. Expressed differently, a core design competence has not only a great strategic value, it is also expensive to make it sustainable.

Coupling the project domains and the core competence domain: It is worth noting that in Fig. 1, there is no direct relationship between the dependency matrix and the criteria tree. 
Indeed, the design managers should use these two complementary tools. With the former tool, they represent the architectures of the project domains along with their couplings. With the latter tool, they evaluate the design capability produced by design organizations (which belong to the organization domain) with regard to distinctive requirements (which belong to the product domain) and project goals (which belong to the process domain). This requires a great change in strategic management practices as managers have to focus on organizational entities, design processes, project goals, and systems requirements simultaneously. There is no existing algorithm to couple the use of the so-called tools and domains automatically. Combining DSM and DMM is a quite recent approach, which does not propose mature and tested tools. However, partial couplings and propagations can be formalized, as it will be shown in this paper.

\section{B. Requirements and Steps of the Approach}

The approach we propose aims at supporting the activities of the design managers, which are related to core competence diagnosis. It is divided into five steps as follows.

1) Design contextualization. As is underlined by evolutionary economics and strategic management theorists, a core competence building is contingent and path-dependent [6], [8]. It refers to a specific context (type of requirements, product lines, economical constraints, design practices, etc.), the design managers have to take into account.

2) The identification of the expectations related to the design core competence. The aim of this step is to identify and elicit the core competence criteria the project team has to meet.

3) Modeling of product, process, and organizational architectures and their interdependencies. The aim is to propagate distinctive requirements through the product architecture and the design process architecture in order to qualitatively identify, which teams' capabilities contribute to meet them.

4) Identification of the value-creating network. The aim is to build a clear cartography of the relationships between the integrated design office and the set of teams within the suppliers involved in the design project.

5) Ex-postevaluation of the produced design capability. A qualitative evaluation of strategic criteria can be performed at the end of the system development project.

\section{Particular Case of the Robotized Gearbox Project}

This part presents a case study that concerns the organizational change process that transformed an old project organization, which designs mechanical gearboxes, into a new organization responsible for the development of more complex robotized gearboxes. We applied the proposed method to diagnose the resulting design capability. Our aim was to represent the architecture of the produced capability, to visualize how it had been embodied in the design teams involved in the valuecreating network, to evaluate it and to discuss its strengths and weaknesses.

\section{A. Design Contextualization}

The case described in the following sections comes from research collaboration (2000-2006) with a French automaker design office. This organization of 4400 designers is specialized in powertrain and chassis development. This design office took into consideration the principles of systems engineering, since 1997 when it was restructured, benefiting from a methodological transfer from aeronautics. It is responsible for both routine and innovative designs. It exploited well-known purely mechanical solutions, and then, ensured the technological continuity of the line of products. But it also had to produce a continuous flow of effective innovations, in order to offer differentiated cars, which would achieve strict requirements (drivability, safety, consumption, $\mathrm{CO}_{2}$ emissions, etc.). The following points explain why the powertrain system design is complex.

1) In functional terms, the size of the requirements list is important. The target level of each of them (safety, gas emission, consumption, drivability, etc.) is higher and higher. The contradictions between them are acute (e.g., a better safety at a lower weight, etc.).

2) In structural terms, each powertrain system includes tens of functional modules and thousands of components.

3) In behavioral terms, it is a dynamic system, which is used in many external environments. Moreover it is coupled to other dynamic subsystems (e.g., chassis).

Moreover, the powertain system is produced by massproduction manufacturing systems, which are organized following the principles of the "Toyota production system" [57]. The fixed costs are high. The powertain system has a longer lifecycle than the ones of vehicle models in which it is integrated. During its life, a powertrain knows several vintages and evolutions. Thus, designers have developed a product family, not a single product. Moreover, innovation is forecast and controlled. A technological continuity exists between the vintages of the product.

The presented case refers more particularly to a subsystem of the powertrain, which is the gearbox. Gearboxes are critical components of the vehicle cinematic chain. For a long time, gearboxes have been well-known mechanical systems. Innovation in this field has been more incremental than radical and there has been a clear dichotomy between manual and automatic gearboxes. The system studied is a new robotized gearbox, which is a technological hybrid between manual and automatic gearboxes. This technical solution is part of a growing class of modules in the automotive industry, which is that of mechatronic subsystems. The concept of the robotized gearbox is to plug a mechatronic actuator (ACT) on a standard manual gearbox with a low cost and a long life cycle. These last points explain how a robotized gearbox can act as an automatic gearbox, and be a cheap solution. There is a potential market for the robotized gearbox: customers who are interested in driving without being disturbed by gearshifting, but who cannot afford an automatic gearbox. Designers involved in the robotized gearbox project had to make what the biologist Stephen Jay Gould (19412002) has called "exaptation" [58]. That is to say, in the present case, exploit as far as possible the potential of current products 
(manual gearbox and compact electrical ACT), the capabilities of design organizations (automaker's design teams), and the growing capabilities of the suppliers involved in the development of subsystems (they try to offer the same solution to several automakers), to open a new product line. It is to be noted that the development of a robotized gearbox is neither a routine design, nor an advanced one.

\section{B. Identification of the Expectations Related to the Design Core Competence}

From the driver's point of view, a car can be considered as an object, which provides a set of services. These services concern the entire vehicle. Thus, design teams need to decompose them into well-defined expectations linked to the car subsystems, e.g., the powertain and the gearbox. The main distinctive requirements can be abstracted from the requirements or constraints allocated to the robotized gearbox.

1) Shifting gears at less than $250 \mathrm{~ms}$, for the feeling of security and the driver's pleasure (or drivability) given by this short time.

2) Contributing to the reduction of $\mathrm{CO}_{2}$ emissions (compliance with very strict Euro $\mathrm{V}$ standards), and to the improvement of fuel consumption.

3) Being as reliable as a manual gearbox.

4) Being an intermediate solution, between cheap manual gearboxes and expensive automatic ones.

In addition to this list of requirements, the goals of the robotized gearbox design project contribute to some of the core competence criteria. In this case, the expected gearbox design capabilities must do the following.

1 Give a provisory leadership in robotized gearboxes in the B segment of the car market (subcompact cars) and erase the place of the automatic gearbox in this segment.

2 Use the same manufacturing system as the one dedicated to a manual gearbox once again. This kind of production system is both capitalistic (high level of fixed costs), and well-known (it is nearly 20 years old). In other words, robotized gearboxes can be seen as an innovative variant of a gearbox platform.

3 Develop a line of products, which are compliant with environmental and social values.

4 Develop an in-house, technical, and organizational learning, which is related to the codevelopment of key mechatronic modules (specification, functional modeling, and validation).

5 Improve the efficiency of collaboration and cross-learning with first tier suppliers.

6 Improve operational performances of projects concerning future designs of mechatronic systems (in particular, the project risks must be managed rigorously, the project duration must be shorter than 120 weeks).

\section{Modeling of Product, Process, and Organizational Architectures and their Interdependencies.}

After identifying the context of the gearbox design and the design core competence expectations, we needed to model the

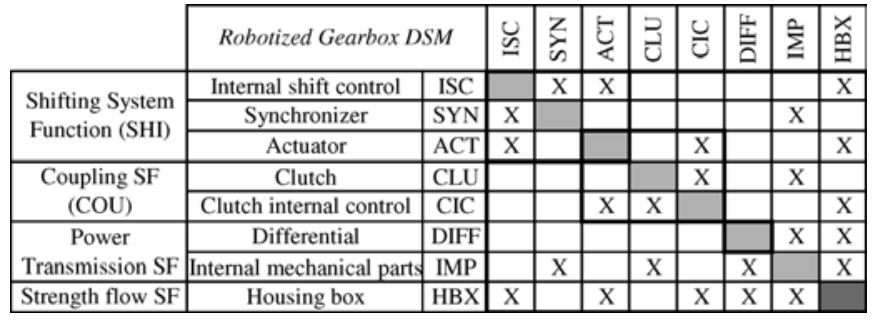

Fig. 2. Product DSM of the robotized gearbox.

dependencies between the product (here, a robotized gearbox), the design process, and the design organization. This needed to be done in order to estimate any possible impacts of distinctive requirements on design organizations, and to highlight crucial design organizations and their capabilities.

1) Product Architecture: Firstly, we interviewed design experts and architects who had a thorough understanding of gearbox architectures. The system architect identified four main system functions (SF): shifting, coupling, power transmission, and strength flow. For the transformation of a manual gearbox into a robotized one, an ACT was to replace the gearshift lever and the clutch pedal. The designed robotized gearbox was composed of eight components, and hundreds of parts. The mapping between functions and components was facilitated by the typicality of the architecture of the robotized gearbox. In this project, the system architect defined an architecture, where an electrical ACT acted both on the internal shift control (ISC) and the clutch internal control (CIC). Fig. 2 displays its hybrid architecture which was composed of following:

1) three modules (or modular subsystems): (ISC; synchronizer (SYN); ACT); (ACT; clutch (CLU); CIC); (differential (DIFF));

2) two integrative subsystems: they linked the other modules of the gearbox together, internal mechanical parts (IMP) from the inside and the housing box (HBX) from the outside.

In this product architecture, each module was directly linked to a system function. Concerning the integrative components, the "IMP" were linked to the differential through the fulfillment of the power transmission function. The HBX directly supported the strength function. Moreover, the system architect stressed that distinctive requirements were carried out by different functions. Drivability was carried out by a modular subsystem (system function: gearshifting; related components: ISC, SYN, and ACT). Power transmission and shifting functions contributed to fuel consumption improvement. Coupling and strength were internal functions. The technical risks management had identified the SYN and ACT as being the most critical components concerning reliability as the gear teeth of the SYN (form and material) had to be modified because of the high strength provided by the ACT. In addition, the ACT included electronic devices and its introduction was innovative. Consequently, the "gearshifting" subsystem had a significant impact on distinctive requirements.

2) Design Process Architecture: Once the robotized gearbox architecture was defined, we interviewed the project 


\begin{tabular}{|c|c|c|c|c|c|c|c|c|c|c|c|c|c|}
\hline & & $\bar{E}$ & 8 & 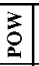 & 总 & $\begin{array}{lll} \\
\end{array}$ & & U & 8 & & & & $\overline{\underline{\prime}}$ \\
\hline Negociate specifications & 0RG1 & $\mathbf{x}$ & $\mathbf{x}$ & $\mathbf{x}$ & $\mathbf{x}$ & & & & & & & & \\
\hline Specify POW function & 1RG1 & & & $\mathbf{x}$ & & & & & & & & & \\
\hline Specify COU function & 1RG2 & & $\mathbf{x}$ & & & & & & & & & & \\
\hline Specify STR function & 1RG3 & & & & $\mathbf{x}$ & & & & & & & & \\
\hline Specify SHI function & 2RG1 & $\mathbf{x}$ & & & & & & & & & & & \\
\hline Fix kinematics & 3RG1 & $\mathbf{x}$ & $\mathbf{x}$ & 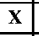 & $\mathbf{x}$ & & & & & & & & \\
\hline Fix axle spread & 4RG1 & & & \begin{tabular}{c|ccc}
$x$ \\
\end{tabular} & & & & & & & & & \\
\hline Fix Clutch Internal Control & 4RG2 & & $\mathbf{x}$ & & & & & & & & & & \\
\hline Fix lubricant & 4RG3 & & & & $\mathbf{x}$ & & & & & & & & \\
\hline Fix Gearbox architecture & 5RG1 & $\mathbf{x}$ & $\mathrm{x}$ & \begin{tabular}{|l|}
$\mathbf{x}$ \\
\end{tabular} & $\mathbf{x}$ & & & & & & & & \\
\hline $\begin{array}{l}\text { Design ACT } \\
\end{array}$ & 6RG1 & $\mathbf{x}$ & & & & $\mathbf{x}$ & & & & & & & \\
\hline Design SYN & 6RG2 & $\mathbf{x}$ & & & & & $\bar{x}$ & & & & & & \\
\hline Design IS & 6RG3 & $\mathbf{x}$ & & & & & & $\mathbf{x}$ & & & & & \\
\hline Design CLU & 6RG4 & & $\mathrm{x}$ & & & & & & $\mathbf{x}$ & & & & \\
\hline Design CI & 6RG5 & & $\mathrm{x}$ & & & & & & & $\bar{x}$ & & & \\
\hline Design D & 6RG6 & & & $x$ & & & & & & 2 & $\bar{x}$ & & \\
\hline Design IMP & 6RG7 & & & $\mathrm{x}$ & & & & & & & & $\underline{x}$ & \\
\hline Design HBX & 6RG8 & & & & $\mathbf{x}$ & & & & & & & & $\mathbf{x}$ \\
\hline Fix rolling bearings and casing & 7RG1 & & & & & & & & & & & $\frac{\bar{x}}{x}$ & \\
\hline Fix components design & 8RG1 & & & & & & & & & & & $\bar{x}$ & $\mathbf{x}$ \\
\hline $\begin{array}{l}\text { Edit integration and validation } \\
\text { document }\end{array}$ & 9RG1 & $\mathbf{x}$ & $\mathbf{x}$ & $\mathbf{x}$ & $\boldsymbol{X}$ & $\mathbf{x}$ & $\mathbf{x}$ & $\mathbf{x}$ & $\mathrm{x}$ & $\mathbf{x}$ & & & $\mathbf{x}$ \\
\hline
\end{tabular}

Fig. 3. Dependencies between robotized gearbox and design process.

design manager to establish the design process architecture. On the left side of Fig. 3, we enumerated a list of tasks included in the design process. Fig. 3 displays the mapping matrix between robotized gearbox and design process (robotized gearbox - process DMM). In the columns, we listed both functions and components as they are objects of different design tasks. We can notice that the shifting function, and consequently drivability, is linked to eight activities. The task "specify shifting function" ("2RG1") is constrained by the specification of the other system functions through the kinematics choice. This mapping matrix also reveals three sets of tasks (this note is consistent with the principles of systems engineering): functional analysis (from ORG1 to 2RG1). system architecture definition (from 3RG1 to 5RG1), and component design (from 6RG1 to 9RG1).

Fig. 4 displays the design process architecture. Partitioning algorithms could be used "for getting the DSM in an uppertriangular form at the extent possible" [29]. In fact, to obtain this list of tasks and this sequence, the MGT interviewed gearbox design experts, discussed about interfaces and deliverables, and then, streamlined the development process. The process DSM revealed that the development process had been organized according to three main stages corresponding to the three sets of tasks mentioned earlier. The level of detail proposed in this paper is sufficient to cover key design tasks and is consistent with the detail level adopted in the gearbox architecture.

The stage of system architecture definition was important to allow concurrent engineering for component design tasks and to decrease the risks of long iterations (regular technical reviews have been planned, but not represented in the process DSM). The design process architecture and project management proved to be competitive as the project duration was shorter than the target duration (120 weeks). The managers' abilities to redesign appropriate design processes contributed to the improvement of the operational performance and the compliance with the target of time to market.

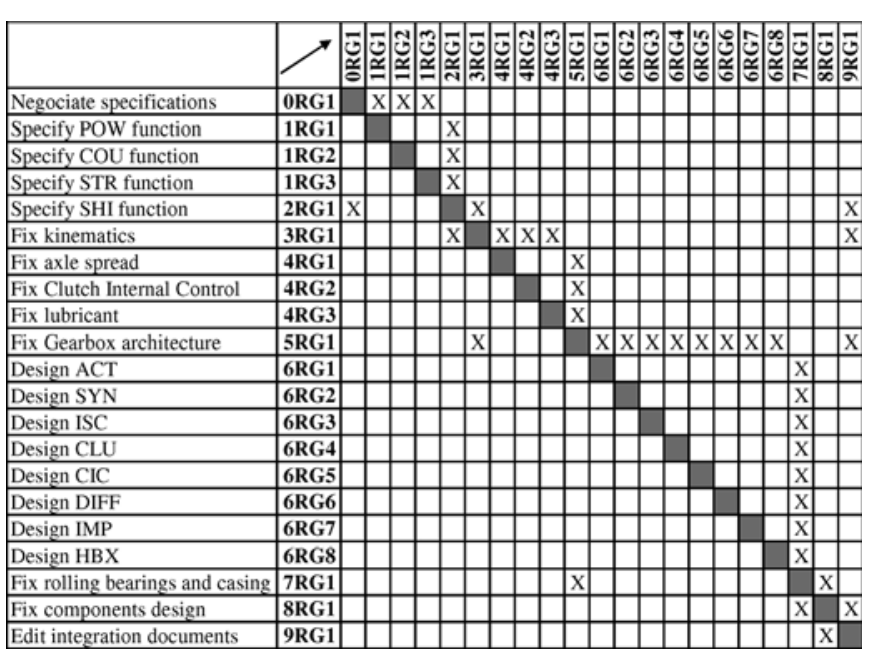

Fig. 4. Design process DSM.

\begin{tabular}{|c|c|c|c|c|c|c|c|c|c|c|c|c|c|c|}
\hline \multicolumn{2}{|l|}{ Organization DMM } & \begin{tabular}{|l|l|} 
& $\mathbf{5}$ \\
$\mathrm{y}$ & $:$ \\
\end{tabular} & & & 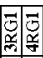 & & & & & & & & & \\
\hline \begin{tabular}{|l|} 
Project manager \\
\end{tabular} & MGT & $\mathrm{x}$ & & & $\mathbf{x}$ & & $\mathrm{x}$ & & & & & & $\mathbf{x}$ & \\
\hline Power transmission function architect & $\mathbf{A}$ & $\mathbf{x}$ & & & $\mathbf{x}$ & & & & & & & & & \\
\hline \begin{tabular}{|l|} 
Coupling function architect \\
\end{tabular} & COUA & & $\mathrm{x}$ & & & $\mathrm{x}$ & & & & & & & & \\
\hline Strength function architect & STRA & & & $\mathrm{x}$ & & $\mathrm{x}$ & & & & & & & & \\
\hline Shifl function architect & SIIIA & & & $\mathbf{x}$ & & & & & & & & & & \\
\hline Actuator devclopment leader & ACTL & & & & & & & $\mathbf{x}$ & & & & & & \\
\hline \begin{tabular}{|l|l} 
Synchronizer development leader \\
\end{tabular} & SYNL & & & & & & & $\mathbf{x}$ & & & & & & \\
\hline Internal shift control devel. leader & ISCL & & & & & & & & $\mathrm{x}$ & & & & & \\
\hline \begin{tabular}{|l|} 
Clutch development leader \\
\end{tabular} & CLUL & & & & & & & & & $\mathrm{x}$ & & & & \\
\hline Clutch internal control devel. leader & CICL & & & & & & & & & $\mathbf{x}$ & & & & \\
\hline Differential development leader & DIFL & & & & & & & & & & $\mathbf{x}$ & & & \\
\hline Internal mechanical parts devel. leader & IMPL & & & & & & & & & & $\mathbf{x}$ & $\bar{x}$ & & \\
\hline housing box development leader & HIEXL & & & & & & & & & & & $\mathbf{x}$ & & \\
\hline Simulation and Ivaluation Leader & St:L & & & & & & & & & & & & & $\mathrm{x}$ \\
\hline
\end{tabular}

Fig. 5. Organization process DMM.

3) Organizational Architecture: This design process was quite new in gearbox development projects. These changes implied the definition of new types of teams and design roles or positions. They induced the restructuring of competence-based design organizations, which developed capabilities to design functional modules.

We captured the design organization by identifying the new roles and their responsibilities, and consequently, the technical interactions between them. The left side of Fig. 5 displays the list of roles of the team members. According to the detail level adopted in the core competence analysis, operational designers do not appear in the proposed DMM in Fig. 5. This DMM is a mapping between the project tasks and the individual roles. In order to avoid conflicts, there is only one decision maker in charge of each design task, but the outsourced components were codesigned with the suppliers' teams. The organizational architecture is obtained by documenting the interactions between actors during the development project. We interviewed the MGT, the system function architects, and the component development leaders to assess the integration effort of design organizations [29]. We asked them to rate the criticality of their interactions with one another during the gearbox definition phase and the detail design phase. In the proposed method, we are interested in a qualitative evaluation only and a binary scale is sufficient. 


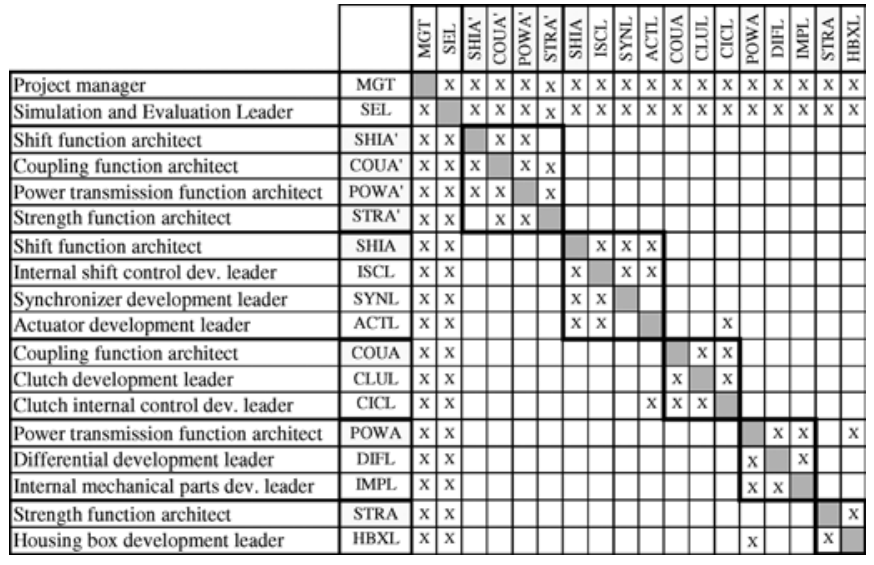

Fig. 6. Organization DSM.

Fig. 6 displays the binary organization DSM and the resulting architecture, where " $\mathrm{X}$ " means that information flows were identified between two actors. We checked the consistency of the design managers' answers and interviewed some actors again to check that they agreed with each other. We rearranged the original DSM and introduced redundant roles of function architects to highlight their key roles. This architecture was validated by the MGT.

We noticed that the MGT, and the simulation and evaluation leader (SEL) were two integrative actors. They interacted with every actor during the project. This information is consistent with the combination between the gearbox - process DMM, the process DSM, and the organization DMM. In fact, the MGT was in charge of tasks 0RG1, 3RG1, 5RG1, and 8RG1 (negotiate specifications, fix kinematics, fix gearbox architecture, fix components design, respectively). These tasks were related to the others, which were under the responsibility of all the designers. The SEL was in charge of the task 9RG1 (edit integration documents), which consisted of risk synthesis for all functions and components. Skills necessary to play these key roles were related to coordination, integration, and a thorough knowledge of mechatronic systems.

The architecture of the robotized gearbox project was complex. There was a central organization called the "system integration team," which regrouped the MGT, the system function architects (power transmission, coupling, strength, and shift function architects), and a SEL who is charge of the management of risks. This crucial team was in charge of key design stages related to functional specification, system architecture, and also system integration and requirement validation. This team developed the capability to design hybrid architectures of robotized gearboxes and the capability to integrate relatively complex systems.

Each system function architect was responsible for the integration of the functional module. She/he managed a modular development team composed of component development leaders, since his/her role was to allocate functional requirements onto concerned components. This leads us to conclude that each function architect has played an integrative role inside his modular team and an engineering liaison role between the concerned
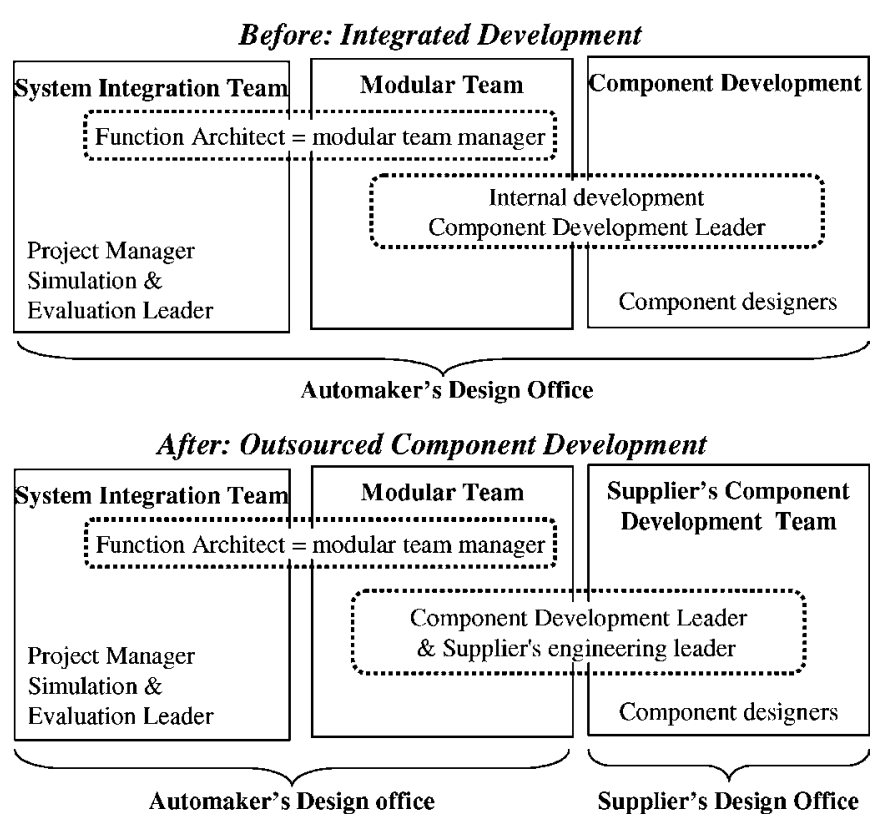

Fig. 7. Key links within organization domain.

component development teams. For instance, the actors linked to gearshifting (and then, drivability) formed a crucial modular team: shift function architect (SHIA), internal shift control development leader (ISCL), synchronizer development leader (SYNL), and actuator development leader (ACTL).

Fig. 7 is based on Fig. 6. It shows the key articulation between the automaker's design office and the supplier's one. In the new design organization, component development leaders had a double role. Firstly, they managed a subteam (a component development team). Secondly, they ensured that the collaboration with the suppliers' teams was effective. It was the case in the studied project for the outsourced components: SYN, clutch, and ACT. Concerning this last component, the ACTL was responsible for its specification and validation, its integration in the gearbox, and its adaptation in the powertrain. He led an ACT development team and played an engineering liaison role with the engineering leader of the supplier's development team. The supplier's team had to codesign gearshift strategies (cospecification of the ACT control) and was in charge of the detail design of the ACT control, electrical devices, model-based software, and its mechanical parts. The component development leaders and the suppliers' engineering leaders played a key interface role (engineering liaison, bargaining, etc.) between the teams of both the automaker and its suppliers.

4) Propagation of Requirements Through Architectures: By means of the product DSM and product-process DMM, we were able to link the distinctive requirements, i.e., drivability, fuel consumption, and reliability, to the concerned components and tasks. By continuing the propagation of the requirements "drivability" or reliability, we observed that the "gearshifting" development team developed a capability to design this key functional module that fulfils these requirements. Moreover, the "power transmission" development team was also crucial as it was concerned with the capability related to the fuel consumption 


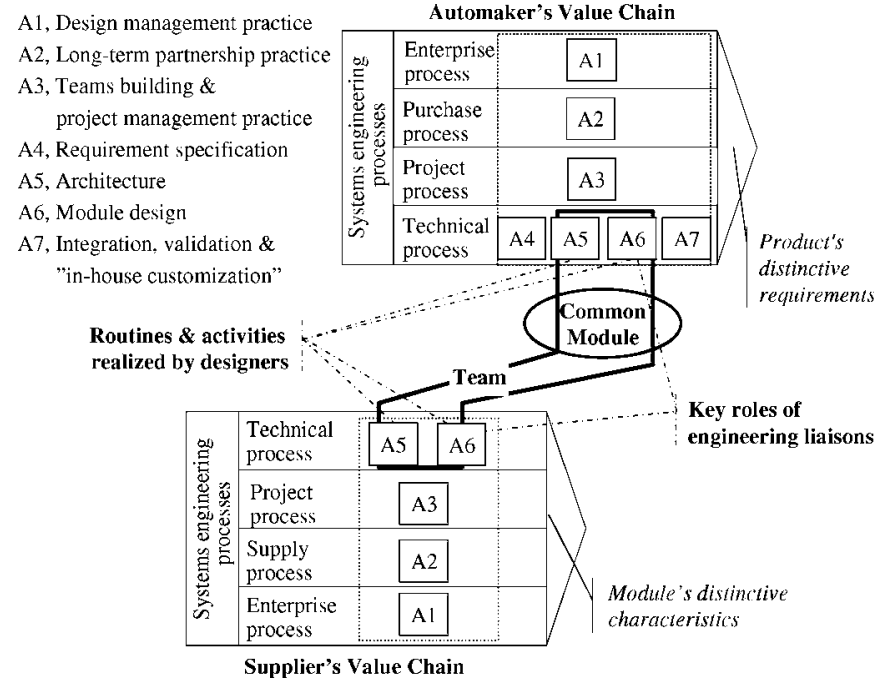

Fig. 8. Value-creating network related to powertrain design.

improvement. In this case study, we were able to associate distinctive requirements to crucial modular teams. The new organizational architecture revealed that the ACTL and the "clutch internal control" development leader (CICL) had played the key role of engineering liaison between two overlapping modules within the automaker's design office.

\section{Identification of the Gearbox Value-Creating Network}

Intrinsic complexity of the powertrain system explains why this product is codesigned by the automaker and a network of suppliers, and why managerial methods. like systems engineering ones are applied [59]. Fig. 8 represents the gearbox-related value-creating network. This figure shows that three entities ensure the cohesion of the network. The first one is the common module, which the automaker's and suppliers' designers develop. The second one is the common or compliant routines, which the automaker's and suppliers' designers have in the field of systems engineering. The last one is the key role of engineering liaisons as previously mentioned.

Gearbox development is a complex and expensive process. The role of the design managers in the car design office and their homologues in the first tier suppliers was to ensure that all the design organizations achieved their operational missions (respect of cost, quality and delay, and risks management). They also had to improve the efficiency of collaboration and crosslearning (cooperative value) by aligning their design organizations (roles of engineering liaisons) and routines. Managers involved in purchase processes had to reduce transaction costs by creating a market framework inside, which the bargaining of automaker-suppliers could be achieved as efficiently as possible.

In this case, such an organizational pattern refers to the ACT, which is a component that highly contributes to distinctive requirements of the robotized gearbox. Therefore, the automaker has selected a supplier to codesign it in the framework of a longterm partnership. The supplier had already developed core competence in designing ACTs of robotized gearboxes for Grand Tourer or F Segment cars. These competencies were comple- mentary to the car design office's ones. At the bargaining process level (purchase versus supply processes), the design managers tried to define the conditions for a long-term "win-win" partnership. The car design office and the suppliers shared a part of their management tools and practices to enhance codesign of hybrid architectures. They defined key engineering liaison roles: the ACTL (the person in charge of developing the ACT within the car design office) and the engineering leader within its supplier. Their project processes shared or developed some collaborative tools in order to virtually integrate module models in the system models (functional, behavioral, and structural models). At an operational level (technical processes), they collaborated to define the ACT control. The supplier of the ACT was strongly involved in the fulfillment of the gearshifting function. However, due to budget restrictions, the car design office temporarily hired engineers who were in charge of specifying the behavior of the ACT and codefining its control system. Hence, the design office did not leverage this project to improve its capability to develop in-house learning, which is related to the codevelopment of key mechatronic modules.

\section{E. Ex-Postevaluation of the Produced Design Capability}

Once the robotized gearbox project was finished, with the design managers, we used in a global and visual way, a qualitative criteria tree to estimate if the capability produced through the project was a core competence or not. Core design competence criteria and their qualitative values are presented in Table I. If all the values were very high, then, in the current market context, the automaker would be the leader in robotized gearboxes for B segment cars (subcompact cars). This however is not the case. It is a credible follower, but not an indisputable leader. In Table I, in the second column, the white squares indicate qualitative criteria estimated by design managers whereas the black ones are related to rough aggregative criteria. The third column corresponds to the design capabilities (identified in Part $\mathrm{B}$ or through the previous diagnosis), which contribute to the automaker's sustainable competitive advantage.

As shown in Table I, the design managers of the car design office conjectured that its external and internal values were high. A design capability in robotized gearbox development was not so common (high value for the rareness criteria linked to the provisory leadership in robotized gearboxes for B segment market cars). The hybridizing process related to the robotized gearbox project produced an efficient outcome. Thus, the system requirements were satisfied (drivability, reduction of $\mathrm{CO}_{2}$ emission, reliability, and cost). Modular teams' capabilities and function architects' roles were able to guarantee the generality of the knowledge acquired at the end of the given project (very high level of sustainability). For example, they were able to increase the level of abstraction of the functional or behavioral models used and produced by mechanical designers. Note that the embeddedness value was too low. A great part of the skills concerning the specification of the controlled behavior was fully outsourced. Thus, the expectation concerning the acquisition of capabilities in codeveloping key mechatronic modules was not satisfied. The estimated value of the "cooperative value" criteria 
TABLE I

DESIGN CORE COMPETENCE CRITERIA TREe RELATED TO THE ROBOTIZED GEARBoX PROJECT

\begin{tabular}{|c|c|c|c|c|c|}
\hline \multirow[b]{2}{*}{$\begin{array}{ll}\text { Design } & \text { Core } \\
\text { Competence } & \\
\text { Criteria } & \end{array}$} & \multicolumn{4}{|c|}{ Criterion level } & \multirow[b]{2}{*}{ Key contributions of design capabilities } \\
\hline & $\bar{\partial}$ & 产 & 旅: & 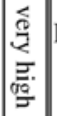 & \\
\hline $\begin{array}{l}\text { Strategic } \\
\text { Characteristic }\end{array}$ & & & - & & $\begin{array}{l}\text { Comment: this aggregated criterion } \\
\text { balances value and cost criteria. }\end{array}$ \\
\hline C1. Global Value & & & - & & \\
\hline C1.1 External Value & & & - & & $\begin{array}{l}\text { Comment: these criteria refer to market } \\
\text { and social viewpoints. They can be } \\
\text { considered as future product } \\
\text { requirements. }\end{array}$ \\
\hline C1.1.1 Rareness & & & $\square$ & & $\begin{array}{l}\text { Give a provisory leadership in the B } \\
\text { segment of the car market by improving } \\
\text { system requirements (like drivability: } \\
\text { shifting gears at less than } 250 \mathrm{~ms} \text {; } \\
\text { reliability: being as reliable as a manual } \\
\text { gearbox ; cost: being an intermediate } \\
\text { solution). }\end{array}$ \\
\hline C1.1.2 Inimitability & & & $\square$ & & $\begin{array}{l}\text { Use the same manufacturing system as } \\
\text { the one dedicated to a manual gearbox } \\
\text { once again (this capability enables } \\
\text { robotized gearboxes to be produced at a } \\
\text { competitive cost by means of } \\
\text { economies of scale) }\end{array}$ \\
\hline $\begin{array}{l}\text { C1.1.3 Regulation } \\
\text { Advance }\end{array}$ & & $\square$ & & & $\begin{array}{l}\text { Develop a line of products which are } \\
\text { more efficient than the regulation } \\
\text { requirements impose (contributing to } \\
\text { the reduction of } \mathrm{CO} 2 \text { emissions) }\end{array}$ \\
\hline $\begin{array}{ll}\text { C1.1.4 Social } \\
\text { Compliance }\end{array}$ & & $\square$ & & & $\begin{array}{l}\text { Develop a line of products which are } \\
\text { compliant with environmental values. }\end{array}$ \\
\hline C1.2 Internal Value & & & - & & $\begin{array}{l}\text { Comment: these criteria refer to the } \\
\text { automaker's and its suppliers } \\
\text { viewpoints. They are related to their } \\
\text { technological trajectory (criterion } \\
1.2 .1 \text { to } 1.2 .3 \text { ) or can be considered as } \\
\text { organizational goals }(1.2 .4 \text { to } 1.2 .7) \text {. }\end{array}$ \\
\hline $\begin{array}{l}\text { C1.2.1 Technical } \\
\text { Complexity }\end{array}$ & & & $\square$ & & $\begin{array}{l}\text { Improve the capability to design hybrid } \\
\text { architectures of mechatronic systems } \\
\text { (like robotized gearboxes). }\end{array}$ \\
\hline C1.2.2 Generality & & & & $\square$ & $\begin{array}{l}\text { Develop the capabilities of modular } \\
\text { teams, and the skills and roles of the } \\
\text { function architects }\end{array}$ \\
\hline $\begin{array}{l}\text { C1.2.3 } \\
\text { Sustainability }\end{array}$ & & & & $\square$ & $\begin{array}{l}\text { Develop model-based function design } \\
\text { practices; improve operational } \\
\text { performances of projects concerning } \\
\text { future designs of mechatronic systems. }\end{array}$ \\
\hline $\begin{array}{|lr|}\text { C1.2.4 } & \text { System } \\
\text { Integration } & \\
\text { Capability } & \\
\end{array}$ & & & $\square$ & & $\begin{array}{l}\text { Develop the capability to integrate } \\
\text { complex systems (system integration } \\
\text { teams). }\end{array}$ \\
\hline $\begin{array}{l}\text { C1.2.5 Module } \\
\text { Development } \\
\text { Capability }\end{array}$ & & $\square$ & & & $\begin{array}{l}\text { Develop the capabilities which are } \\
\text { related to the design of key functional } \\
\text { modules (gear shifting and power } \\
\text { transmission) and key engineering } \\
\text { liaison roles with suppliers. }\end{array}$ \\
\hline $\begin{array}{l}\text { C1.2.6 } \\
\text { Embeddedness }\end{array}$ & & $\square$ & & & $\begin{array}{l}\text { Develop in-house learning which are } \\
\text { related to the co-development of key } \\
\text { mechatronic modules. }\end{array}$ \\
\hline $\begin{array}{l}\text { C1.2.7 Cooperative } \\
\text { Value }\end{array}$ & & $\square$ & & & $\begin{array}{l}\text { Improve the efficiency of collaboration } \\
\text { and cross-learning with first tier } \\
\text { suppliers. }\end{array}$ \\
\hline
\end{tabular}

TABLE I

(CONTINUED)

\begin{tabular}{|l|l|l|l|l|l|}
\hline C2. Global Cost & & - & $\begin{array}{l}\text { lomment: a design core competence is } \\
\text { supposed to be expensive to "own". }\end{array}$ \\
\hline $\begin{array}{l}\text { C2.1 Acquisition } \\
\text { Cost }\end{array}$ & & $\square$ & & $\begin{array}{l}\text { Use tools routinely related to behavioral } \\
\text { modeling and physical testing. }\end{array}$ \\
\hline $\begin{array}{l}\text { C2.2 } \\
\text { Contextualization } \\
\text { Cost }\end{array}$ & & & & $\begin{array}{l}\text { Improve the traceability of the design of } \\
\text { mechatronic subsystems but reduce as } \\
\text { much as possible the capacity of } \\
\text { competitors to imitate this design. }\end{array}$ \\
\hline $\begin{array}{l}\text { C2.3 } \\
\text { Conceptualization } \\
\text { Cost }\end{array}$ & & $\square$ & $\begin{array}{l}\text { Assimilate mechatronic concepts and } \\
\text { up to date modeling techniques. }\end{array}$ \\
\hline $\begin{array}{l}\text { C2.4 Capitalization } \\
\text { Cost }\end{array}$ & $\square$ & & $\begin{array}{l}\text { Re-use of mechatronic models and } \\
\text { design methods in another projects or } \\
\text { product lines }\end{array}$ \\
\hline
\end{tabular}

was medium as no sharing of knowledge between the car design office and its suppliers was achieved through the project. The car design office did not use this project to improve the efficiency of its collaboration and cross-learning with its ACTs' suppliers. The global cost of competence development was high, although most of the components of the gearbox were reused. We can explain this fact by the following rationale: the crucial skills needed in this kind of hybrid architecture design are system-focused (integrative), not modular-focused.

\section{DISCUSSION}

In the car design office, technological knowledge and skills were restructured in competency-based design entities (rather than functional departments), according to the key system functions of the product. This organizational architecture was aligned with the architecture of gearboxes. Each competency-based entity grouped different architects who were responsible for the same function (but involved in different projects), the concerned component development leaders, as well as the in-house component designers. In the system integration team, a function architect represented his/her competency-based entity and was responsible for the fulfillment of the concerned system function. This manager led a small team of component designers who remained in their design entity. This "lightweight project organization" [60] was justified as the interdependencies between the teams were weak at the level of the components and rather high at the function level. The function architect played a key role by developing two main kinds of skills. The first skill was orientated to the development of the team's capability. It was related to synthesis and coordination inside the team that the function architect managed. The other one concerned both the system and the partners involved in the same value-creating network. This last skill was related to integration and negotiation at the interfaces with the other teams.

Function architects had to develop their expertise related to the specification and validation of this function inside the car design office as well as possible. Otherwise, the automaker could have become strongly dependent on its suppliers. As far as the "transaction costs" theory [34] is concerned, the long-term 
TABLE II

TRAJECTORY OF THE DESIGN CORE COMPETENCE

\begin{tabular}{|c|c|c|}
\hline $\begin{array}{c}\text { Past capabilities } \\
\text { (before the presented } \\
\text { project) }\end{array}$ & $\begin{array}{l}\text { Current capabilities } \\
\text { (after the presented } \\
\text { project) }\end{array}$ & $\begin{array}{l}\text { Future capabilities } \\
\text { (expected projects) }\end{array}$ \\
\hline $\begin{array}{l}\text { Design of B segment } \\
\text { mechanical gearbox }\end{array}$ & $\begin{array}{l}\text { Design of B segment } \\
\text { robotized gearbox }\end{array}$ & $\begin{array}{l}\text { Design of B segment } \\
\text { robotized double clutch } \\
\text { gearbox }\end{array}$ \\
\hline $\begin{array}{l}\text { Past competitive } \\
\text { advantage : low cost } \\
\text { reliable gearbox }\end{array}$ & $\begin{array}{l}\text { Current competitive } \\
\text { advantage : low cost } \\
\text { reliable gearbox with a } \\
\text { high level of drivability } \\
\text { (capabilities: give a } \\
\text { provisory leadership in } \\
\text { the B segment market; } \\
\text { develop a line of } \\
\text { products) }\end{array}$ & $\begin{array}{l}\text { Expected competitive } \\
\text { advantage : higher } \\
\text { drivability than an } \\
\text { automatic gearbox for a } \\
\text { much lower price (the } \\
\text { capability to develop a } \\
\text { line of products will be } \\
\text { even more crucial to } \\
\text { reduce the costs of } \\
\text { development and } \\
\text { manufacturing) }\end{array}$ \\
\hline $\begin{array}{l}\text { Importance of the detail } \\
\text { design of the } \\
\text { mechanical parts. No } \\
\text { real system integration. } \\
\text { Gearbox integration is } \\
\text { achieved by pure } \\
\text { mechanical solutions } \\
\text { (e.g. gearbox carter). }\end{array}$ & \multicolumn{2}{|c|}{$\begin{array}{l}\text { Importance of the capability related to system } \\
\text { definition and integration at the powertrain } \\
\text { subsystem level (the whole gearbox). } \\
\text { Growing importance of the capability related to } \\
\text { system integration (supported by both mechanical } \\
\text { and software-oriented solutions) and to the design } \\
\text { of hybrid architectures. }\end{array}$} \\
\hline $\begin{array}{l}\text { Integrated design office } \\
\text { (only parts are } \\
\text { outsourced) }\end{array}$ & $\begin{array}{l}\text { Development of a } \\
\text { value-creating network } \\
\text { based on the } \\
\text { outsourcing of } \\
\text { components (like the } \\
\text { actuator) }\end{array}$ & $\begin{array}{l}\text { A value-creating network } \\
\text { based on the outsourcing } \\
\text { of modules: the ever } \\
\text { increasing importance of } \\
\text { the capability to develop } \\
\text { in-house learning related } \\
\text { to the co-development of } \\
\text { mechatronic modules }\end{array}$ \\
\hline $\begin{array}{l}\text { Empiric synthesis based } \\
\text { on realistic prototypes } \\
\text { (e.g. CAD files) }\end{array}$ & $\begin{array}{l}\text { Increase in the } \\
\text { capability to develop } \\
\text { model-based function } \\
\text { synthesis }\end{array}$ & $\begin{array}{l}\text { The more important role } \\
\text { of proof models for } \\
\text { embedded software }\end{array}$ \\
\hline $\begin{array}{l}\text { Part-focused functional } \\
\text { departments }\end{array}$ & \multicolumn{2}{|c|}{$\begin{array}{l}\text { Competency-based design entities. Increasing } \\
\text { importance of the capabilities to integrate complex } \\
\text { systems and to design key functional modules } \\
\text { (modular vs. integration teams) and key engineering } \\
\text { liaison roles with suppliers }\end{array}$} \\
\hline $\begin{array}{l}\text { Internal embodiment of } \\
\text { design core competence } \\
\text { (automaker's } \\
\text { mechanical experts own } \\
\text { the whole competence) }\end{array}$ & \multicolumn{2}{|c|}{$\begin{array}{l}\text { Long-term partnership between the value-creating } \\
\text { network's partners (the competence is shared and } \\
\text { co-developed between the automaker and its } \\
\text { suppliers). Growing importance of the capability to } \\
\text { improve the efficiency of collaboration and cross- } \\
\text { learning with first tier suppliers }\end{array}$} \\
\hline
\end{tabular}

partnership for future and more complex gearbox development projects is required.

The team in charge of the shifting module design developed a capability related to the knowledge of mechatronic engineering as this module was made of mechanical parts, ACTs, sensors, and a control system. This capability was shared between the car manufacturer and the supplier of the ACT as they cospecified the expected behavior of the robotized gearbox and covalidated the working of this module. The supplier was selected early on in the innovation phase according to its capability to be (or to become) an innovative integrator of this mechatronic component.
The team responsible for the power transmission module developed a specialized capability, i.e., thorough expertise relative to a particular function. It is similar for the designers in charge of the SYN design inside the shifting module team, since it is a mechanical component.

In this design office, the knowledge transfer between different projects was facilitated within the competency-based entities by communities of practice, which were led by a "technological leader". Moreover the system project team included functional support representatives (for instance, planning, quality, accounting, and test), which were multiproject at the same time, and then, also shared new innovative solutions throughout the gearbox development projects quickly.

Table II sums up the main changes made to the car design office's gearbox design capabilities. It shows that the acquired capabilities related to the robotized gearbox project are likely to be extended to future innovative gearboxes.

The new gearbox is a significant innovation within the B market due to cost savings in a potential future key market. Modularity is a key paradigm for architecturing project domains and facilitates the development of key design capabilities. It favors both incremental innovations and the development of the capabilities of design organizations. The main risk of the modular strategy adopted by the design office, is that a competitor may develop a radical innovation, which may cause the existing firms to lose the leading market positions. This could be the case if an automaker (or even an outsider) launches electric cars with a price comparable to the existing standard of the B segment market.

\section{CONCLUSION}

This paper presents an approach to diagnose design core competence. We outlined how to link competence-based and valuecreating network management, with matrix-based architecture models. Well-known tools in the fields of strategic management or design management were used to identify the structure (i.e., DSM) or the coupling (i.e., DMM) between three project domains (product, design process, and organization) linked to the design core competence management. These matrix-based models helped to propagate new distinctive requirements onto design organizations involved in a common value-creating network (integrated design offices, suppliers' design offices, and teams). The different types of capabilities belonging to the teams could be identified when the organizational architecture was revealed (modular, integrative, and overlapping). A core competence criteria tree was also proposed, in order to evaluate if a produced design capability following a given product development project could be considered as a core competence or not. We presented a set of criteria, which extend the set of usual ones (rareness, inimitability, and embeddedness) by adding external criteria (compliance with social values and regulation advance), internal ones (technical complexity and cooperative value), and also the global cost of the competence (acquisition, contextualization, conceptualization, and capitalization). 
The strategic management literature fails to propose a framework, which jointly evaluates the produced capabilities following a product development project and which represents its architecture (at least partially), that is to say, the way it is embedded in the value-creating network involving several independent design offices. The case study presented in this paper focused on a design office that had restructured its organization to achieve better alignment with the architecture of the complex products it develops. However, a new alignment is not sufficient to ensure the firm's sustainable competitive advantage. Design managers will have to adapt the managerial roles, practices, and strategies to better integrate the in-house design teams and the suppliers' teams into an efficient value-creating network. The proposed method will help design managers to evaluate new design organizations, to determine if the produced capability actually corresponds to a design core competency, to represent the architecture of the design organizations that embed this core competence, and then, to identify the crucial teams and managerial roles.

The case study corresponds to another experience concerning the interest of alignment in case of modular architectures. The proposed method should help researchers to study the interest of alignment in terms of core competence development and according to different product architectures, organizational boundaries, and competitive environments.

It provides researchers with a consistent framework concerning design core competence diagnosis. Our proposition could be extended to develop a global framework and recommendations concerning competency-based management of valuecreating networks. However we need to find answers to the following questions: What would be the target of the design core competence? How would the gap between the expected core competence and the current routines of existing design organizations be measured? How would the appropriate architectures be? What would be the new managerial roles and practices?

Finally, further work is envisaged. Other applications are necessary to improve the proposed method. In our approach, DMM are used in the same way as the Japanese quality function deployment (QFD) method [61]. DMM and QFD matrices (called "house of quality") can be used to deploy the choice made in one domain into another domain, from system requirements, to the product, to the design process, and ultimately to the design organizations. The similarity may be used to better formalize the approach for propagating goals or the "voice of the end user". For instance, project goals may be propagated in such a way by introducing new goals in the process domain (such as the delay reduction). The main difficulty may be explained by the fact that some core competence criteria are holistic. They cannot be easily deployed. They do not concern the components of the dependency matrices, but the overall project. For instance, market or social criteria can be considered as project goals, which all design teams must take into account and which have an impact on all subsystems, be they modular or integrative. In this paper, we were concerned with a diagnosis of core competence, and not with the specification and deployment of new core competence criteria (organization design). In an organization design phase, it may be useful to develop a QFD "house of quality" to analyze how the elements in the different project domains may contribute to the fulfillment of the core competence criteria. This tool may help the design managers to deploy strategic goals on the different project domains. However, the QFD methodology is neither focused on the architecture of each domain, nor on the coupling between modules that belong to different domains.

The case studied in this paper dealt with hybrid architecture with three clearly identified modules from functional and physical points of view. This starting point facilitated the propagation of distinctive requirements (drivability and reliability, in this paper) through organizational and design process architectures, and also in the identification of the capabilities of crucial teams. A qualitative approach is certainly sufficient to achieve a global diagnosis. The challenge is now to study the design core competence concerning a system that is "less modular". The development of propagation algorithms and tools would be useful to simulate the quantitative impacts related to the changes of the distinctive requirements in the project domains, to propagate the "voice of the end user" or to make some insights of the designers more effective [7]. In the case of an integral architecture, this propagation is obviously more difficult and would require further investigations.

\section{ACKNOWLEDGMENT}

The authors would like to thank the design managers of the automaker's design office for their fruitful collaboration. We also thank the department editor, Prof. J. Pinto, and the anonymous reviewers who suggested useful improvements in the drafts of this paper.

\section{REFERENCES}

[1] Y. Droz, "Managing core competency for corporate renewal: Towards a managerial theory of core competencies," in Core Competency-Based Strategy, A. Campbell and K. Sommers Luchs, Eds. London, U.K.: International Thomson Business Press, 1997, pp. 53-74.

[2] R. Sanchez, "Analyzing internal and competitor resources, capabilities, and management processes," in The Oxford Handbook of Strategy: A Strategy Overview and competitive Strategy, D.-O. Faulkner and A. Campbell, Eds. New York: Oxford Univ. Press, 2002, pp. 350376.

[3] J.-B. Barney, "Firm resources and sustained competitive advantage," $J$. Manage., vol. 17, no. 1, pp. 99-120, 1991.

[4] T. Felin and N.-J. Foss, "Organizational routines and capabilities: Historical drift and a course-correction toward microfoundations," Scandinavian J. Manage., vol. 25, no. 2, pp. 133-145, 2009.

[5] C. McDermott and T. Coates, "Managing competencies in breakthrough product development: A comparative study of two material processing projects," IEEE Trans. Eng. Manage, vol. 54, no. 2, pp. 340-350, May 2007.

[6] D-G. Sirmon, S. Gove, and M-A. Hitt, "Resource management in dyadic competitive rivalry: The effects of resource bundling and deployment," Acad. Manage. J., vol. 51, no. 5, pp. 919-935, 2008.

[7] R. Lester and M. Piore, Innovation: The Missing Dimension. Cambridge, MA: Harvard Univ. Press, 2004.

[8] R. R. Nelson and S. G. Winter, An Evolutionary Theory of Economic Change.. Cambridge, MA: Harvard Univ. Press, 1982.

[9] S. L. Pan, G. Pan, A. J. W. Chen, and M. H. Hsieh, "The Dynamics of implementing and managing modularity of organizational routines during capability development: Insights from a process model," IEEE Trans. Eng. Manage, vol. 54, no. 4, pp. 800-813, Nov. 2007. 
[10] R. Sanchez and A. Heene, "Competence-based strategic management: Concepts and issues for theory, research, and practice," in Competencebased Strategic Management, R. Sanchez and A. Heene, Eds. New York: Wiley, pp. 3-27, 1997.

[11] M. Danilovic and T. R. Browning, "Managing complex product development projects with design structures matrices and domain mapping matrices," Int. J. Project Manage., vol. 25, pp. 300-314, 2007.

[12] A. MacCormack, J. Rusnak, and C. Baldwin. (2008). "Exploring the Duality between Product and Organizational Architectures: A Test of the Mirroring Hypothesis," Working Paper 08-039, Harward Business School, Boston, MA [Online]. Available: SSRN: http://ssrn. com/abstract= 1104745 .

[13] M. Danilovic and P. Leisner, "Analyzing core competence and core products for developing agile and adaptable corporation," presented at the Conference DSM. Munchen, D: 16-17, Oct. 2007.

[14] R. Gulati and S. Eppinger, "The coupling of product architecture and organizational structure decisions," MIT Sloan Working Paper no. 3906. Cambridge, MA, 1996.

[15] B. Oosterman, "Improving product development projects by matching product architecture and organization," Ph.D. thesis. Gröningen Univ., Gröningen, NL, 2001.

[16] M. E. Sosa, S. D. Eppinger, and C. M. Rowles, "The misalignment of product architecture and organizational structure in complex product development," Manage. Sci., vol. 50, no. 12, pp. 1674-1689, 2004

[17] P. Kothandaraman and D. T. Wilson, "The Future of competition: Valuecreating networks," Ind. Marketing Manage., vol. 30, no. 4, pp. 379-389, 2001

[18] R. Lamming, T. Johnsen, J. Zhurong, and C. Harland, "An initial classification of supply networks," Int. J. Oper. Prod. Manage., vol. 20, no. 6, pp. 675-691, 2000.

[19] J. McGee, "Strategy as orchestrating knowledge," in Images of Strategy, S. Cummings D. Wilson Eds. Malden, MA: Blackwell, pp. 136-163, 2005

[20] Y-K. Ro, J. K. Liker, and S. K. Fixson, "Modularity as a strategy for supply chain coordination: The case of U.S. auto," IEEE Trans. Eng. Manage., vol. 54, no. 1, pp. 172-189, Feb. 2007.

[21] G. Hamel and C. K. Prahalad, Competing for the Future. Cambridge, MA: Harvard Business School Press, 1994.

[22] K. Haafez, Y. Zhang, and N. Malak, "Core competence for sustainable competitive advantage: A structured methodology for identifying core competence," IEEE Trans. Eng. Manage., vol. 49, no. 1, pp. 28-35, Feb. 2002

[23] G. Pépiot, N. Cheikhrouhou, J-M. Furbringer, and R. Glardon, "A fuzzy approach for the evaluation of competences," I. J. Prod. Econ., vol. 112, pp. 336-353, 2008.

[24] C.-M. Christensen, The Innovator's Dilemma: The Revolutionary Book That will Change the Way You Do Business. New York, NY: Harper Collins, 2003.

[25] C. Haskins, Systems Engineering Handbook. A Guide for System Life Cycle Processes and Activities, International Council on Systems Engineering (INCOSE)-TP-2003-002-03.1. Seattle, WA. 2007.

[26] H.-A. Simon, The Sciences of the Artificial. Cambridge, MA: MIT Press, 1997.

[27] K-T. Ulrich, "The role of product architecture in the manufacturing firm," Res. Policy, vol. 24, pp. 419-440, 1995.

[28] C.-Y. Baldwin and K-B. Clark, Design Rules: The Power of Modularity Design. Cambridge, MA: MIT Press, 2000.

[29] T.-R. Browning, "Applying the design structure matrix to system decomposition and integration problems: A review and new directions," IEEE Trans. Eng. Manage, vol. 48, no. 3, pp. 292-306, Aug. 2001 .

[30] N. Suh, Principles of Design. Cambridge, U.K.: Oxford Univ. Press, 1990.

[31] J. Jiao, T. Simpson, and Z. Siddique, "Product family design and platformbased product development: A state-of-the-art review," J. Intell. Manuf., vol. 18, no. 1, pp. 5-29, 2007.

[32] R. Sanchez, "Modular architectures, knowledge assets and organisational learning: New management processes for product creation," Int. J. Technol. Manage., vol. 19, no. 6, pp. 610-629, 2000.

[33] R. Balachandra, Modular design and technological innovation: The case of the hard disk drives. Rep. 2002-02, The Inf. Storage Ind. Center, Univ. California, 2002

[34] O.-E. Williamson, The Economic Institutions of Capitalism: Firms, Markets, Relational Contracting. New York: The Free Press, 1985.
[35] M. E. Sosa, S. D. Eppinger, and C. Rowles, "Designing modular and integrative systems, presented at the ASME 2000 Int. Des. Eng. Tech. Conf. (DETC) Baltimore, MD.

[36] M. E. Sosa, S. D. Eppinger, and C. Rowles, "Identifying modular and integrative systems and their impact on design team interactions," Trans. ASME J. Mech. Des., vol. 125, pp. 240-252, 2003.

[37] K. R. McCord and S. D. Eppinger, "Managing the integration problem in Concurrent Engineering," MIT Sloan School of Management Working Paper no. 3594. Cambridge, MA, 1993.

[38] T. R. Browning, "Designing system development projects for organizational integration," Syst. Eng., vol. 2, no. 4, pp. 217-225, 1999.

[39] S. D. Eppinger and V. Salminen, "Patterns of product development interactions," in Proc. Int. Conf. Eng. Des. ICED), Glasgow, U.K., Aug. 21-23, 2001, vol. 1, pp. 283-290.

[40] K. T. Ulrich and S.D. Eppinger, Product Design and Development. New York: McGraw Hill, 2000.

[41] R. I. Whitfield, J. S. Smith, and A. H. B. Duffy, "Identifying component modules," in Proc. 7th Int. Conf. Artif. Intell. Des. (AID), Cambridge, U.K., 15-17 Jul. 2002, pp. 571-592.

[42] T. U. Pimmler and S. D. Eppinger, "Integration analysis of product decompositions," in Proc. ASME Des. Theory Method Conf. (DTM 1994), vol. 68, pp. 343-351.

[43] P. J. Clarkson, C. S. Simons, and C.M. Eckert, "Predicting change propagation in complex design," ASME J. Mech. Des., vol. 126, no. 5, pp. 765-797, 2004

[44] J. Malmqvist, "A classification of matrix based methods for product modelling," presented at the Design 2002, Cavtat-Dubrovnik, Croatia.

[45] S. J. Chen and L. Lin, "Decomposition of interdependent task group for concurrent Engineering," Comput. Ind. Eng., vol. 44, pp. 435-459, 2003.

[46] M. Danilovic and T. Browning, "A formal approach for domain mapping matrices (DMM) to complement design structuring matrices (DSM)," presented at the 6th Int. Des. Struct. Matrix (DSM) Workshop, Cambridge, U.K., Sep. 12-14, 2004.

[47] E. Bonjour, S. Deniaud, M. Dulmet, and G. Harmel, "A fuzzy method for propagating functional architecture constraints to physical architecture," Trans. ASME, J. Mech. Des, vol. 131, no. 6, pp. 061002-1-061002-11, Jun. 2009.

[48] R. P. Steward and V. Donald, "The Design Structure System: A method for managing the design of complex systems," IEEE Trans. Eng. Manage, vol. EM-28, no. 3, pp. 71-74, Aug. 1981.

[49] A. Yassine and D. Braha, "Complex concurrent engineering and Design Structure Matrix method," Concurr. Eng.: Res. Appl., vol. 11, no. 3, pp. 165-176, 2003.

[50] T. R. Browning and S. D. Eppinger, "Modeling impacts of process architecture on cost and schedule risk in product development," IEEE Trans. Eng. Manage., vol. 49, no. 4, pp. 428-442, Nov. 2002.

[51] S. D. Eppinger, R. S. Whitney, and D. Gebala, "A model-based method for organizing tasks in product development," Res. Eng. Des., vol. 6, no. 1, pp. 1-13, 1994.

[52] U. Lindemann, "A vision to overcome chaotic "design for X" processes in early phases," presented at the Int. Conf. Eng. Des. (ICED), Paris, 28-31 Aug. 2007.

[53] X. Boucher, E. Bonjour, and B. Grabot, "Formalisation and use of competences for industrial performance optimisation: A survey," Comput. Ind., vol. 58, no. 2, pp. 98-117, 2007.

[54] C.-H. Fine, Clockspeed: Winning Industry Control in the Age of Temporary Advantage. Reading, MA: Perseus Books, 1998.

[55] (2001). Object Management Group, OMG Unified Modeling Language Specification, v1.4 (OMG, September 2001). [Online]. Available: http://www.uml.org.

[56] P.-H. Hsieh, C. S. Mishra, and D. H. Gobeli, "The return on R\&D versus capital expenditures in pharmaceutical and chemical industries," IEEE Trans. Eng. Manage, vol. 50, no. 2, pp. 141-150, May 2003.

[57] T. Ohno, Toyota Production System: Beyond Large-Scale Production. Cambridge, MA: Productivity Press, 1988.

[58] S. J. Gould, The Structure of Evolutionary Theory. Cambridge, MA: Harvard Univ. Press, 2002.

[59] H. Proff, "A competence-based approach to understanding the orchestration of value chains in the development of "new" value architectures," Adv. Appl. Bus. Strategy, vol. 11, pp. 93-115, 2008.

[60] C. Wheelwright and K. B. Clark, Revolutionizing Product Development: Quantum Leaps in Speed, Efficiency, and Quality. New York: The Free Press, 1992

[61] Y. Akao, Quality Function Deployment, QFD - Integrating Customer Requirements into Product Design. Cambridge, MA: Productivity Press, 1990. 


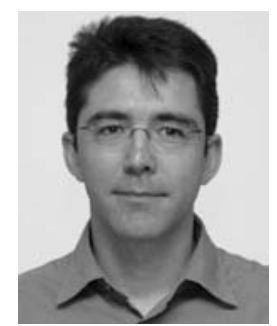

Éric Bonjour received the M.S. (Engineer) degree in mechanical engineering from the Engineering Institute of Besancon (ENSMM), France, in 1993 and the Ph.D. degree in automation from the University of Besançon, France, in 1996.

$\mathrm{He}$ is currently an Associate Professor with the University of Franche-Comté (UFC), Besançon, France. For six years, he has led a research project in collaboration with a French car manufacturer in the field of project management, competence management, and systems engineering. He has published more than 40 papers for journals, such as the Journal of Mechanical Design, the Computers in Industry, and the International Journal of Product Development, and conferences.

Prof. Bonjour is a member of International Council on Systems Engineering (INCOSE) and has been leading a Technical Committee of the Assimilated French INCOSE Chapter (Association Française d'Ingénierie Système).

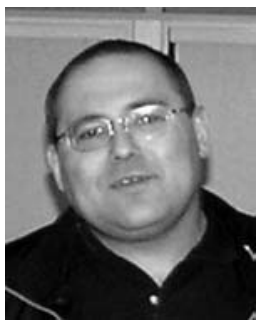

Jean-Pierre Micaëlli received the Ph.D. degree in economics, in 1994.

He is currently an Associate Professor in industrial management with the Institut National des Sciences Appliquées Lyon, University of Lyon, Villeurbanne Cedex, France. He has been engaged in several collaborative research projects with automakers, automotive suppliers, aircraft manufacturers, and engineering firms. His current research includes developing new applications in the field of computer-aided evaluation in design. He has published six books and more than 30 papers for books, journals, and conferences. 